Article

\title{
Climate and Extreme Rainfall Events in the Mono River Basin (West Africa): Investigating Future Changes with Regional Climate Models
}

\author{
Ernest Amoussou 1,2,3,4**, Hervé Awoye 5,6 ${ }^{1}$, Henri S. Totin Vodounon ${ }^{1,2}$, \\ Salomon Obahoundje ${ }^{3}$ (D) Pierre Camberlin ${ }^{4}$ (D), Arona Diedhiou ${ }^{3,7}$ (D), Kouakou Kouadio ${ }^{3,8,9}$ (D), \\ Gil Mahé ${ }^{10} \mathbb{D}$, Constant Houndénou ${ }^{2}$ and Michel Boko ${ }^{2}$ \\ 1 Département de Géographie et Aménagement du Territoire, Université de Parakou, Parakou BP 123, Benin; \\ sourouhenri@yahoo.fr \\ 2 Laboratoire Pierre PAGNEY, Climat, Eau, Ecosystème et Développement (LACEEDE), Université \\ d'Abomey-Calavi, Cotonou 03 BP1122, Benin; constant500@yahoo.fr (C.H.); bokomichel@gmail.com (M.B.) \\ 3 African Centre of Excellence on Climate Change, Biodiversity and Sustainable Development, Université \\ Félix Houphouët Boigny (UFHB), 22 B.P. 582 Abidjan 22, Cote D’Ivoire; obahoundjes@yahoo.com (S.O.); \\ arona.diedhiou@ird.fr (A.D.); kk.kouadio@yahoo.fr (K.K.) \\ 4 Centre de Recherches de Climatologie (CRC), Biogéosciences, Université de Bourgogne, 6 boulevard Gabriel, \\ F-21000 Dijon, France; camber@u-bourgogne.fr \\ 5 Laboratoire d'Hydraulique et de Maîtrise de l'Eau (LHME), Université d'Abomey-Calavi, \\ Cotonou 01 BP 526, Benin; herve.awoye@gmail.com \\ 6 Department of Geography, University of Calgary, Calgary, AB T2N 1N4, Canada \\ 7 Institute of Research for Development IRD, CNRS, Grenoble INP, IGE, University Grenoble Alpes, \\ F-38000 Grenoble, France \\ 8 Laboratory of Atmosphere Physics and Fluid Mechanics, UFHB, 22 BP 582 Abidjan 22, Cote D'Ivoire \\ 9 Geophysical Station of Lamto (GSL), N’Douci BP 31, Cote D'Ivoire \\ 10 IRD, Laboratoire HydroSciences de Montpellier, Université de Montpellier 2, Case courrier MSE, Place \\ Eugène Bataillon, 34095 Montpellier CEDEX 5, France; gil.mahe@ird.fr \\ * Correspondence: ernestamoussou@gmail.com; Tel.: +229-95064746
}

Received: 28 November 2019; Accepted: 21 January 2020; Published: 16 March 2020

\begin{abstract}
This study characterizes the future changes in extreme rainfall and air temperature in the Mono river basin where the main economic activity is weather dependent and local populations are highly vulnerable to natural hazards, including flood inundations. Daily precipitation and temperature from observational datasets and Regional Climate Models (RCMs) output from REMO, RegCM, HadRM3, and RCA were used to analyze climatic variations in space and time, and fit a GEV model to investigate the extreme rainfalls and their return periods. The results indicate that the realism of the simulated climate in this domain is mainly controlled by the choice of the RCMs. These RCMs projected a 1 to $1.5^{\circ} \mathrm{C}$ temperature increase by 2050 while the projected trends for cumulated precipitation are null or very moderate and diverge among models. Contrasting results were obtained for the intense rainfall events, with RegCM and HadRM3 pointing to a significant increase in the intensity of extreme rainfall events. The GEV model is well suited for the prediction of heavy rainfall events although there are uncertainties beyond the 90th percentile. The annual maxima of daily precipitation will also increase by 2050 and could be of benefit to the ecosystem services and socioeconomic activities in the Mono river basin but could also be a threat.
\end{abstract}

Keywords: Mono basin; extreme rainfall events; ENSEMBLE; regional climate models 


\section{Introduction}

Climate change represents the latest in a series of environmental drivers of human conflict that have been identified in recent decades, following others, including drought, desertification, land degradation, failing water supplies, deforestation, fisheries depletion, and even ozone depletion [1]. Extreme hydroclimatic events, such as heavy rainfall, floods, and droughts, have detrimental effects on local populations and their socioeconomic environment. With the projected increase in the atmospheric greenhouse gases concentration, it is important to investigate the future evolution of the frequency and intensity of these extreme events [2-4]. In this respect, sub-Saharan Africa is greatly concerned because the populations are highly vulnerable and hydroclimatic phenomena are responsible for the majority of the reported victims of the natural hazards the region has experienced [5]. In the Gulf of Guinea, the Mono river basin, which extends over Benin and Togo, is influenced by two types of climate: A subequatorial climate in the south and a tropical wet climate over the rest of the watershed to the north. This climatic pattern is constrained by the seasonal shift of the Intertropical Convergence zone and associated lower and upper tropospheric flows over West Africa [2]. Interannual variations of these features as well as short-term rainfall and temperature variations result in a succession of drought and flood events. With ongoing global warming, we may experience an increasein rainfall intensity in the watershed [6]. Indeed, previous studies reported more frequent extreme rainfall events in many regions of the world and predicted increases in the future flood frequency in the West African Sahel $[4,7]$.

The climate degradation could generate conflicts of water resource usage mainly in the transboundary basins. As most West African basins are trans-boundaries, this could be a source of conflict among different sectors of water users [8,9]. Brown and Crawford [10] proved that climate change has increased the conflict risk in trans-boundaries river basins like Volta shared by Burkina and Ghana. Additionally, as West African sub-Saharan agriculture systems are mainly rainfed agriculture systems, then any change or variation in rainfall could affect the production, and consequently lead to food insecurity. Moreover, the increase in temperature could accelerate the evaporative loss, and thus increase water competition [11-13].

Climate change impacts were previously assessed using raw simulations from global climate models (GCMs), which operate at coarse spatial resolutions ranging from 150 to $400 \mathrm{~km} \mathrm{[14-17].} \mathrm{Thus,}$ the information generated by these models does not always match ground observations because GCMs do not explicitly consider the spatial heterogeneity of land surface conditions [18]. In addition, these models impose limits on the representation of certain atmospheric phenomena (e.g., mesoscale processes, localized orographic ascendance, etc.) $[18,19]$. The expected changes derived from GCM simulations should be considered with caution for climate impact and adaptation studies [3,20]. A more convenient way of assessing climate change impact on water resources, ecosystems, and agriculture is to use global climate model projections downscaled at a finer scale [21-24]. Many statistical approaches are used to downscale the coarse resolution GCM simulations and better account for the local or regional effects of topography, land use, and other forcings $[3,17,25,26]$. An alternative to statistical downscaling is dynamical downscaling with regional climate models (RCMs). With their higher spatial resolution as compared to GCMs, RCMs account for greater topographic diversity and more localized atmospheric dynamics [27]. Their ability to reproduce the main characteristics of hydro-climatological dynamics during extreme rainfall events has been demonstrated [28]. This good performance is mainly due to the higher spatial resolution of RCMs that better match the spatial scales at which mesoscale convective processes occur [29]. Despite these improvements, we still need to validate the RCM simulations before using them for climate change impact studies because they still feature systematic biases, which vary substantially from one model to another.

The aims of this paper were to assess the historical and future changes in key climatic variables (e.g., near-surface air temperature and precipitation, extreme rainfall) in the Mono river basin and derive conclusions regarding their impact on flood dynamics in the watershed upstream of the hydroelectric dam of Nangbéto. The RCM simulations over West Africa developed in the frame of the European 
project ENSEMBLES, CMIP5, and CORDEX-Africa. We assessed the performance of four RCMs to reproduce the mean air temperature, precipitation, and extreme rainfall events. An analysis of the changes in these climatic variables over $2028-2050$ as projected by each RCM is presented, with an emphasis on the frequency and intensity of daily rainfall events. The selected RCMs were driven by two GCMs in order to assess the robustness of the simulations and the role of large and regional scales in the model differences. However, for this typical work, it was applied to a small watershed scale, like the Mono river basin.

This work is structured as follows: The study area is described followed by the used data; the statistical methods used for data analysis are presented as well; next, the results focus on the relevance of climatic fields and regimes simulated by the selected RCMs, the expected changes in mean near-surface air temperature, mean precipitation, the frequency and return periods of extreme rainfall events, and their potential impacts on the catchment hydrology and; finally, the results are discussed and some perspectives are highlighted.

\section{Study Area}

The Mono river basin is in West Africa and extends over $560 \mathrm{~km}$ from the north to the south [2]. This transboundary watershed covers $15,680 \mathrm{~km}^{2}$ and is shared by Benin and Togo (Figure 1). This watershed is home to the Nangbéto hydroelectric dam that has been providing electricity to Benin and Togo since September 1987. As this hydroelectric dam is modifying the hydrology of the river, the main part of this study will focus on the Mono river basin upstream of the dam.

This watershed is patterned in the south by floodplains and plateaus, and higher landforms in the north and north-west, e.g., the Atakora Mountains with a height of $800 \mathrm{~m}$ and their southern extensions that are the Togo mountains.

Precipitation in Togo and Benin is constrained by the organization of the atmospheric circulation over West Africa as a whole, i.e., both that of the lower layers (humid monsoon flow from the southwest, and dry Harmattan flow from the northeast) and the flow of air in the lower troposphere and upper atmosphere (respectively African Easterly Jet (AEJ) and Tropical Easterly Jet (TEJ)) [2]. At the scale of the Mono river basin, this circulation is strongly linked to the energy gradients between the coastal plain and the Gulf of Guinea. The precipitations are also modulated by the interaction of the southwesterly humid monsoon flow and the landforms in the northwestern part of the watershed. The average annual precipitation ranges from $900 \mathrm{~mm}$ in the southeast, i.e., in the plains along the dry diagonal in the south of Togo, to $1200 \mathrm{~mm}$ in the northwestern uplands. There are two climatic domains in the basin: The subequatorial domain in the southern part of the basin with two rainy and two dry seasons and the tropical domain in the northern part with one rainy season and one dry season.

The hydrological regime is of a humid tropical type and consistent with the tropical climate that governs it. The uneven distribution of precipitation combined with heavy rainfall events over very short periods leads to recurring flooding events. These phenomena are aggravated by the increase in surface runoff due to land cover degradation [30]. As a result, the local population or riparian and their properties and livelihoods are more vulnerable than the population living upstream of the basin as evidenced by the severe floods of the past 12 years in the lower valley of the Mono river basin. 


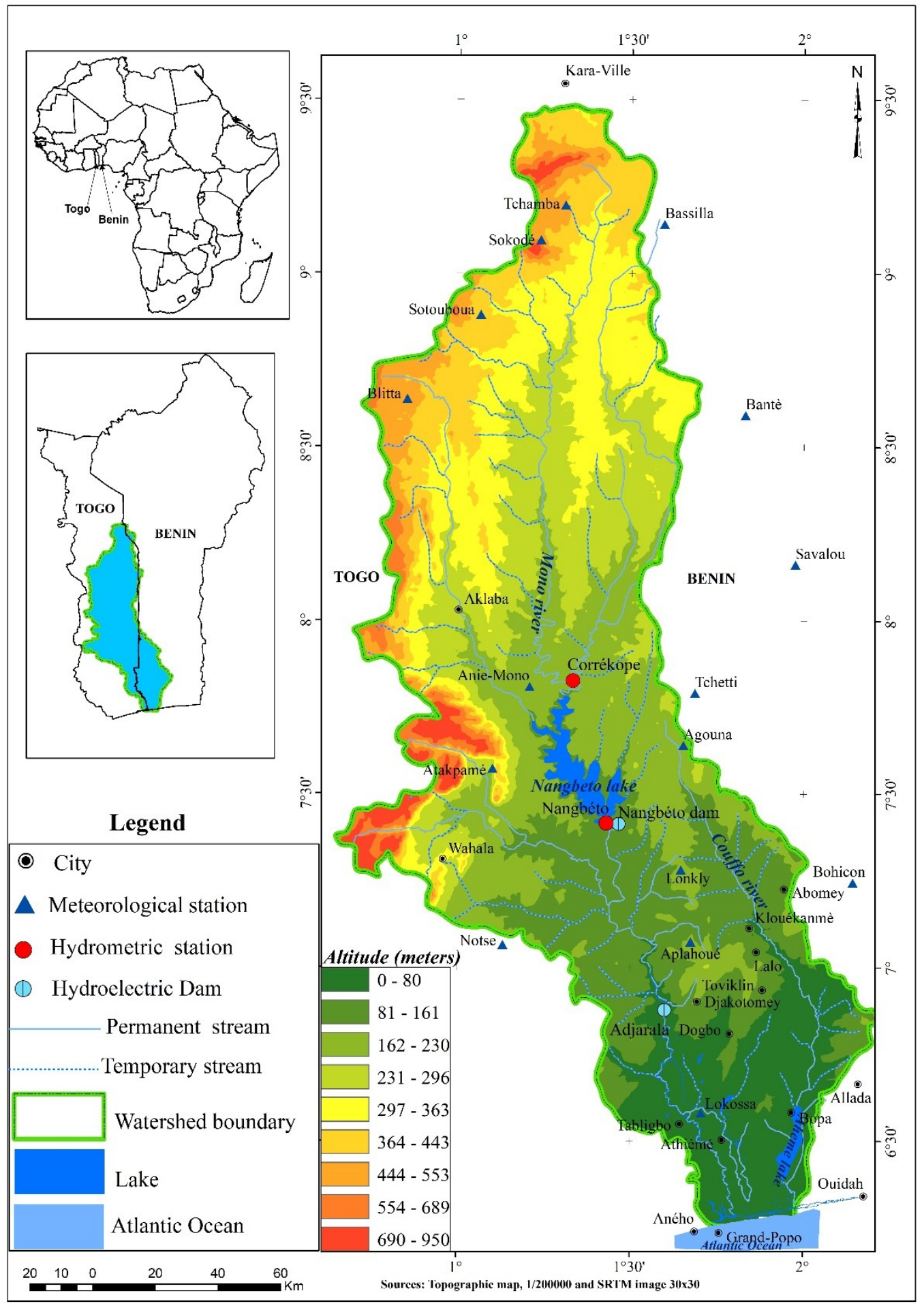

Figure 1. Location of the rainfall (blue triangles) and hydrometric stations (red dots) in the Mono river basin between Benin and Togo.

\section{Materials and Methods}

\subsection{Observational Climate Data}

We used daily rainfall data from 14 rain gauge stations located in the Mono river basin and its close vicinity, and daily near-surface air temperature from two meteorological stations, namely the Bohicon and Nangbéto stations. Those observed data were used to select the closest model to the 
observation (reality) for projection. Thus, the model closest to the reality was used. The data cover a 50-year period (1961-2010) and are provided by the Agency for the Air Navigation Safety in Africa and Madagascar (ASECNA) in Cotonou-Benin, the Direction de la Météorologie Nationale (DMN) of Togo, the Climatology Research Centre (CRC) of the University of Bourgogne in France, and the Global Historical Climate Network (GHCN, [31]).

We compared the gauged rainfall data with the gridded data from the RCM models. The rain-gauge data were spatially interpolated to a $0.5^{\circ}$ resolution upstream of the Nangbéto hydro-electric dam using an ordinary kriging block (Figure 1). A climatological variogram was considered and an adjustment was made to a spherical variogram [22]. The range parameter of the adjusted model is 65 $\mathrm{km}$ and indicates the average distance of precipitation decorrelation between two stations. In contrast, the arithmetic mean of the two observed air temperature stations data was made and then used to compare to the model dataset.

In order to describe the climates that prevail in West Africa and compare them with the RCM simulations, gridded monthly data of precipitation and near-surface air temperature from 3 additional datasets were extracted over the region extending over $5-14^{\circ} \mathrm{N}$ and $1.2-3^{\circ}$ E. These sets of data covering the years from 1988 to 2009 at a $0.5^{\circ}$ spatial resolution are the GPCP Global Precipitation Climatology Project data [32], the near-surface air temperature data from CRU (Climatic Research Unit, [33]). The CRU data is chosen based on its multidiscipline application, namely in applied climatology, biogeochemical modelling, hydrology, and agricultural meteorology domains [33] and its performance [34].

\subsection{Data from Regional Climate Models}

Precipitation and near-surface air temperature data from the selected four RCMs developed in the framework of the ENSEMBLES European project [35] are listed in Table 1. They are extracted from the AMMA-ENSEMBLES database [17]. These RCMs simulations are centered on West Africa $\left(19.8^{\circ} \mathrm{S}-35.2^{\circ} \mathrm{N}\right.$ and $\left.35.2^{\circ} \mathrm{W}-31.2^{\circ} \mathrm{E}\right)$, have a horizontal resolution of $50 \mathrm{~km}$, and cover the period 1951-2050 (1980-2050 for the ICTP model). These RCMs simulations are driven by two CMIP3 global climate models (GCMs), namely ECHAM5 for MPI and ICTP models and HadCM3 for HC (METO) and SMHI models, following the IPCC A1B scenario. We used these RCM simulations at a daily time step for a region extending over $5-14^{\circ} \mathrm{N}$ and $1.2^{\circ} \mathrm{W}-3^{\circ}$ E. METO and SMH simulations follow a 360-day calendar. The 18-year period spanning 1988-2005 was used for the comparison of the precipitation, and air temperature RCMs data with observations (GPCP for precipitation and CRU for temperature) were considered for the air temperature.

Table 1. Selected models.

\begin{tabular}{ccccc}
\hline \multirow{2}{*}{ Model Number } & \multicolumn{2}{c}{ Regional Climate Model (RCM) } & \multicolumn{2}{c}{ Driving Global Climate Model (GCM) } \\
\cline { 2 - 5 } & RCM & Modeling Agency & GCM & Modeling Agency \\
\hline \multicolumn{4}{c}{ CORDEX } \\
$(1)$ & REMO & GERICS & CM5A-LR & IPSL \\
$(3)$ & RegCM4-3 & ICTP & MPI-ESM-MR & MPI-M \\
$(4)$ & REMO & MPI-CSC & MPI-ESM-LR & MPI-M \\
$(5)$ & SMHI & RCA4 & CNRM-CERFACS & CNRM-CM5 \\
$(6)$ & SMHI & RCA4 & CM5A-MR & IPSL \\
& SMHI & RCA4 & MPI-ESM-LR & MPI-M \\
\hline$(7)$ & CMIP5 & CM5 & CNRM \\
$(8)$ & & CM5A-LR & IPSL \\
$(9)$ & & CM5A-MR & IPSL \\
$(10)$ & & ESM-LR & MPI \\
$(11)$ & & ESM-MR & MPI \\
\hline
\end{tabular}


Table 1. Cont.

\begin{tabular}{|c|c|c|c|c|}
\hline \multirow{2}{*}{ Model Number } & \multicolumn{2}{|c|}{ Regional Climate Model (RCM) } & \multicolumn{2}{|c|}{ Driving Global Climate Model (GCM) } \\
\hline & RCM & Modeling Agency & GCM & Modeling Agency \\
\hline \multicolumn{4}{|c|}{ AMMA-ENSEMBLES } & Scenario \\
\hline (12) & RegCM3 & ICTP & ECHAM5 & A1B \\
\hline (13) & HIRHAM & METNO & HadCM3 & A1B \\
\hline (14) & REMO & MPI-M & ECHAM & A1B \\
\hline (15) & RCA & SMHI & HadCM3 & $\mathrm{A} 1 \mathrm{~B}$ \\
\hline
\end{tabular}

NB: MPI-M-Max Planck Institute of Meteorology; MPI-CSC-Climate Service Center, Max Planck Institute for Meteorology; ICTP-International Centre for Theoretical Physics; SMHI-Swedish Meteorological and Hydrological Institute; CNRM-Centre National de Recherches Météorologiques; REMO—Regional Climate Model; RegCM - Regional Climate Model; RCA—Rossby Centre regional atmospheric model; GERICS—Climate Service Center Germany; HadCM3-Hadley Centre Coupled Model.

It is important to note that for the next step, International Centre for Theoretical Physics will be called (ICT); Swedish Meteorological and Hydrological Institute by SMH; Max Planck Institute of Meteorology by MPI, and Hadley Centre Coupled Model by METO.

We extracted the CORDEX, CMIP5, and AMMA-ENSEMBLES outputs over the Mono river basin at the outlet of Nangbéto, computed the spatial ensemble averages of each data type, and compared them with the interpolated (observed) data. Since the streamflow gauge data recorded are only available over 1988-2010, we used the period 1988 to 2010 (23 years) as the reference period and the period 2028 to 2050 (23 years) as the scenario period.

\subsection{Statistical Methods}

Observed and simulated climate data were analyzed for the sub-region and the Mono river basin itself. At the sub-regional scale, seasonal average maps were used to compare simulated precipitation and mean air temperature fields with the observational data over 1988-2010, and to assess the projected future changes for 2028-2050. The RCM whose outputs in the reference period is closer to observations can be considered for future projection.

At the catchment scale, the observed and simulated climate data were also spatially averaged and statistically processed. First, monthly averages of rainfall and air temperature were computed to describe the ability of the regional climate models to reproduce the present-day climatic regimes and to assess the projected future changes (2028-2050). The average frequency of the number of rainy days (i.e., a day with a rainfall amount higher than $1 \mathrm{~mm}$ ) in each grid point in the Mono river basin was also computed. The contribution of the different classes of daily rainfall intensity to the total precipitation recorded on average in the watershed was determined from the calculation of deciles. The 99th percentile is usually used to characterize the extreme events [36-39]. This is the reason why the 99th percentile is used to assess the importance of heavy rains in the basin.

Observed hydroclimatic series do not always meet the assumption of data stationarity $[40,41]$. This is often the case for extreme rainfall and flood discharge. In the literature, some scholars $[42,43]$ have suggested describing the distribution of extreme values with three different types of probability distribution for extreme order statistics while others [44-47] suggested using a generalized extreme value (GEV) distribution, which combines the three types of Fisher-Tippett extreme value distributions [48]. The GEV parameters use the generalized maximum likelihood (GML) method, which includes an additional constraint on the shape parameter to eliminate potentially invalid values of this parameter based on Tramblay et al.'s [4] study.

In this study, we used a GEV distribution to characterize extreme events. In the case of non-stationarity, the GEV parameters are not constant but are dependent on time or other covariates. To avoid having a value of zero for the scale parameter, $\alpha \mathrm{t}$, we considered the parameterization as $\phi \mathrm{t}=\log (\alpha \mathrm{t})$ and thus restricted our analysis to linear dependencies [49]. However, many other types of dependencies can be linearized $[41,44,48,50]$. 
The return periods of a GEV model are defined by the cumulative distribution function (CDF), $\mathrm{F}(\mathrm{x})$, or the probability density function $(\mathrm{PDF}), \mathrm{f}(\mathrm{x})$, hat are given by the formula:

$$
F(x)=\operatorname{Pr}[X \leq x] \text { and } f(x)=\frac{d F(x)}{d x},
$$

where $\operatorname{Pr}$ is the probability of the occurrence of an event and $\mathrm{X}$ stands for the random variable, which in this case is a series of annual daily maxima of rainfall. The quantile value, $Q_{T}$, is a magnitude of the extreme event that has a probability of $1 / \mathrm{T}$ and can be exceeded by a single event. A return period, $\mathrm{T}$, associated with a quantile value, $\mathrm{Q}_{\mathrm{T}}$, was adapted from Stedinger et al.'s [51] equation and can be expressed as:

$$
\mathrm{T}=\frac{1}{\left[1-\mathrm{F}\left(\mathrm{Q}_{\mathrm{T}}\right)\right]}
$$

The selection of the best GEV model adjustment was made by using the deviance test, which is based on the log-likelihood [20].

\section{Results and Discussion}

\subsection{Spatial Distribution of the Annual Rainfall and Air Temperature for Three Datasets}

Figures 2 and 3 present the ensemble average annual rainfall and mean air temperature for the historical period 1988-2005 (first column) and change between the reanalysis (GPCP) and models in (second column) the historical period as well as the projected changes for 2028-2050 (third column).

The spatial distribution of the observed rainfall (1988-2005 annual rainfall average, GPCP data) in the Mono river basin and surrounding areas is presented in Figure 2d. The observed rainfall pattern shows a diagonal axis of a high rainfall amount (over $1320 \mathrm{~mm}$ per year) from south-west to north-east along with the Togo and Atakora mountain ranges. A strong decrease in rainfall is also shown in the north towards the Sahelian zone ( $<600 \mathrm{~mm} / \mathrm{year})$. The GPCp reanalysis data captures the observed precipitation gradient over West Africa well [52] and this finding agrees with the study of Ntajal et al. [49] in Mono basin.

The ensemble averages were computed for CMIP5 and RCP8.5 for CORDEX. The CORDEX (Figure 2c) and CMIP5 (Figure 2b) display a greater rainfall estimation in the historical period compared to the AMMA-Ensemble (Figure 2a) and GPCP (Figure 2d), especially at the southern part. The validation made (second column of Figure 2) exhibits that CMIP5 and CORDEX overestimate the rainfall, which is about $340 \mathrm{~mm} /$ year. Nevertheless, the AMMA-Ensemble gives an estimation closer to the reanalysis $( \pm 20 \mathrm{~mm} /$ year $)$.

There is a projected general decrease varying by 16 to $32 \mathrm{~mm}$ in the annual total precipitation. For instance, the CMIP5 model presents a decrease of about $24 \mathrm{~mm}$ and less than $24 \mathrm{~mm}$, respectively, in the central and southern parts of the basin while the CORDEX estimates a decrease between 24 and $32 \mathrm{~mm}$ in the central and southern part of the basin. Nevertheless, in the northern part of the basin, an increase in the annual total precipitation of around $16 \mathrm{~mm}$ and in the range of 16 to $24 \mathrm{~mm}$ for the CMIP5 and CORDEX models, respectively, is projected. Finally, the AMMA-ENSEMBLES displays a decrease in the projection change ranging from 0 to $32 \mathrm{~mm} /$ year.

The temperature gradient was well shown by all the datasets, which increase in the northern direction (first column of Figure 3). The observed mean air temperature extracted from Climate Research Unit (CRU) varies slightly, with a maximum of $29.5^{\circ} \mathrm{C}$ in the far north (the Sahel in Niger) and a minimum of $26^{\circ} \mathrm{C}$ in altitude on the Togolese ridge (Figure 3d). The AMMA-Ensemble and CORDEX data give an underestimation of the temperature ranging from 0 to $1{ }^{\circ} \mathrm{C}$ while the CMIP5 presents an underestimation between 1 and $2{ }^{\circ} \mathrm{C}$ (second column of Figure 3 ) and the lowest rise is given by AMMA-ENSEMBLES. Unlike the rainfall, there is a very good agreement in the projected changes (increase) of air temperature from the AMMA-Ensemble, CMIP5, and CORDEX dataset. 
The warming is expected to vary between $1.4^{\circ} \mathrm{C}$ in the south to $1.8^{\circ} \mathrm{C}$ towards the north. However, AMMA-ENSEMBLES gives the lowest projected changes among all the models (third column).

The performance of CORDEX RCMs in simulating the spatial distribution of the main precipitation and temperature features as well as the occurrence of other physical phenomena over West Africa was demonstrated by Gbobaniyi et al. [53]. Diallo et al. [54] also showed the importance of the ensemble mean of multiple models. They proved that the RCMs-GCMs alone are biased and these biases are reduced by averaging all RCM simulations, suggesting that multi-model RCM ensembles based on different driving GCMs help to compensate systematic errors from both the nested and the driving models [54]. This justified the use of multiple models. According to IPCC assessment reports, the temperature is projected to increase over West Africa for the end of the 21st century from the global climate simulation range between 3 and $6{ }^{\circ} \mathrm{C}$ above the late 20th century baseline depending on the emission scenario [55]. However, they also revealed that the onset and length of precipitation could also change.

a.)

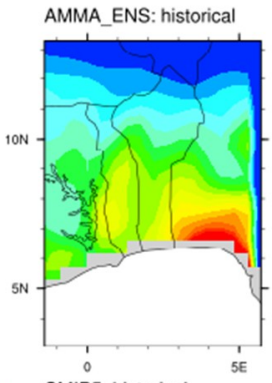

b.)

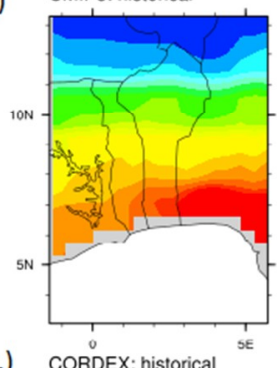

c.) CORDEX: historical

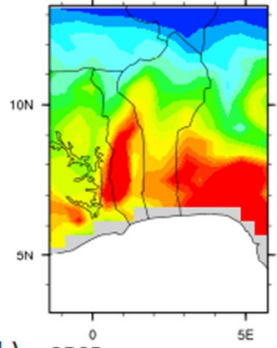

d.)

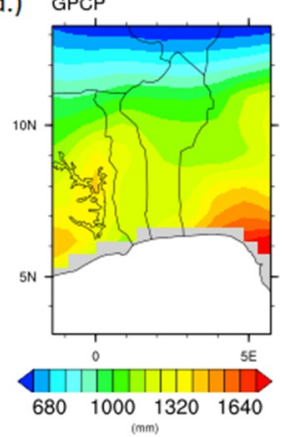

e.)

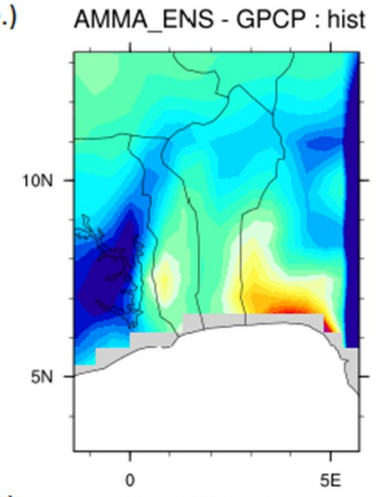

f.)

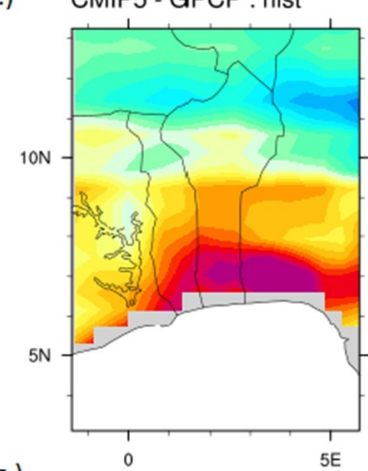

g.)

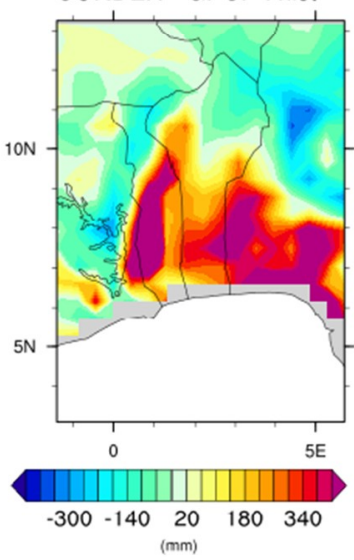

h.) AMMA_ENS: A1B - hist

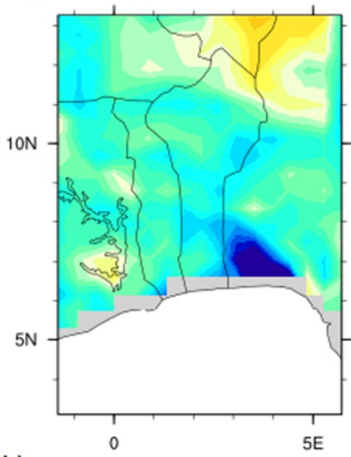

i.) CMIP5: rcp85 - hist

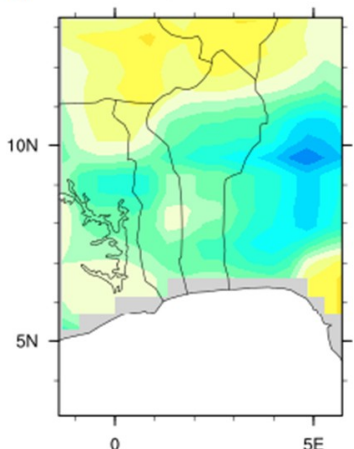

j.) CORDEX: rcp85 - hist

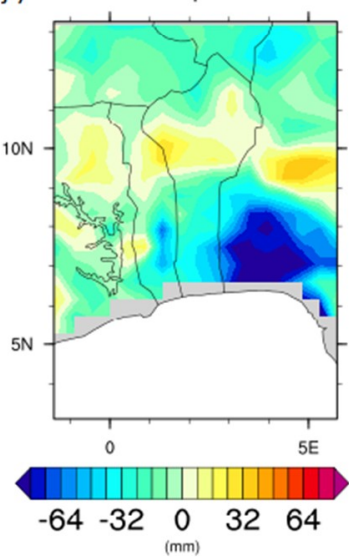

Figure 2. Ensemble average annual mean rainfall for 1988-2005 (first column), validation (second column over 1988-2005 period), and the projected changes with respect to the period 2028-2050 (third column). 


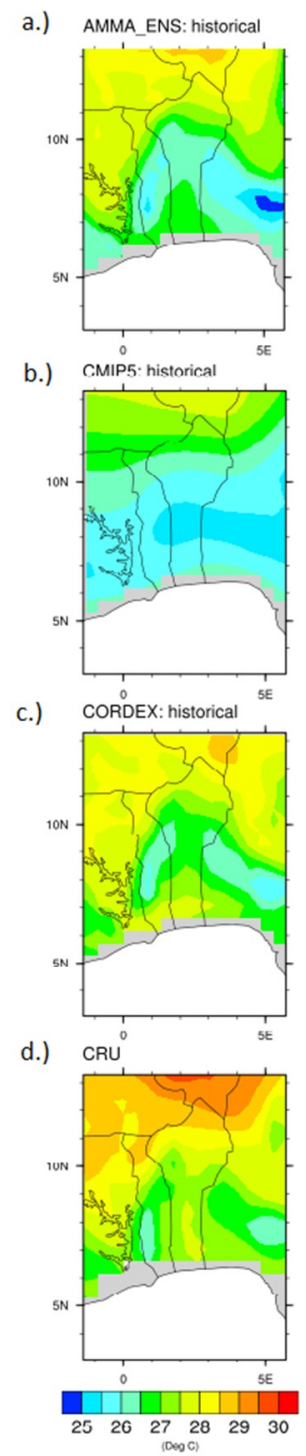

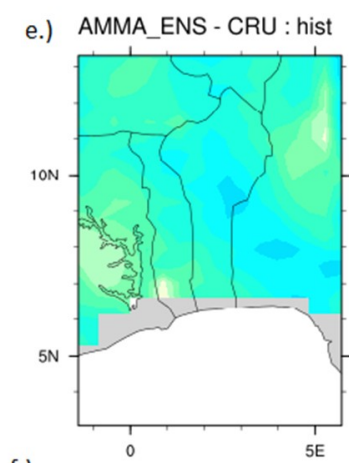
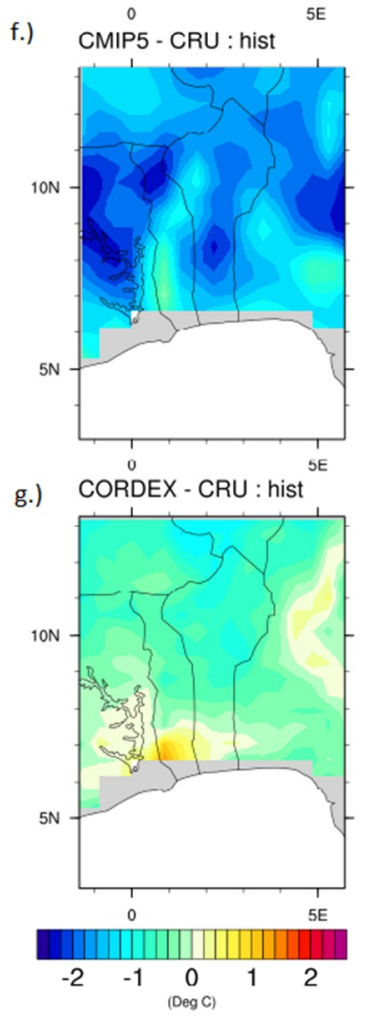

h.) AMMA_ENS: A1B - hist

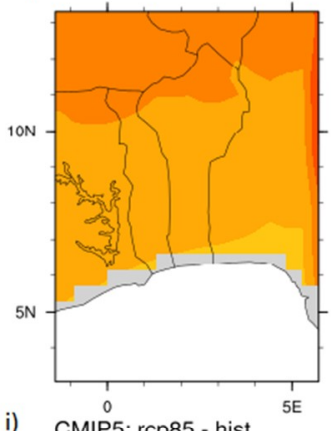

i) CMIP5: rcp85 - hist

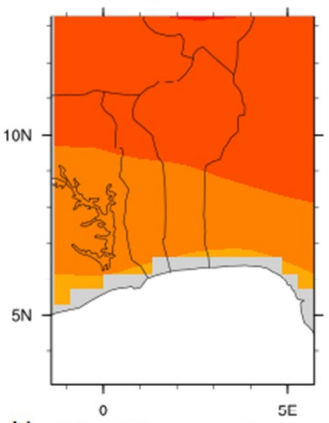

j.) CORDEX: rcp85 - hist

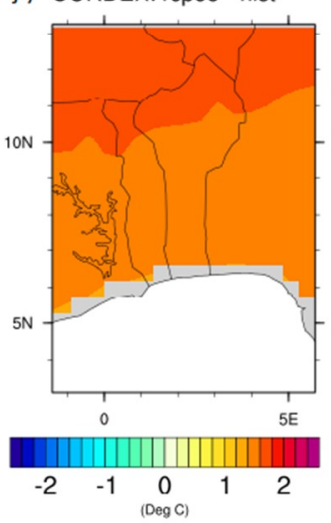

Figure 3. Ensemble average annual mean temperature for 1988-2005 (first column), validation (second column over 1988-2005 period), and the projected changes with respect to the period 2028-2050 (third column).

AMMA-ENSEMBLES data permits a better understanding of the processes underlying the West-African Monsoon (WAM) [56]. It provides and advances an understanding of the atmospheric processes over West Africa [57]. AMMA data were used in climate change assessment in the region. The finding of the current study is in accordance with Angelina et al.'s [58] study on the river Niger basin West Africa. They confirmed that all RCMs of AMMA-ENSEMBLES experiment displays an increase in air temperature while there was no consensus among them in precipitation variables.

\subsection{Spatial Distribution of the Averaged Annual Precipitation and Air Temperature for AMMA-ENSEMBLES Models}

An analysis of Figure 4 shows the simulated AMMA-ENSEMBLES model's precipitation dataset. The total annual precipitation data for the reference period (1988-2010 in the first raw) and projected period (2028-2050 in the second raw) and the changes in projection in the third raw are presented in Figure 4 for the MPI, METO, SMH, and ICT models. The total annual precipitation over the basin varies from 1200 to $1800 \mathrm{~mm} /$ year whatever the model. The total annual precipitation simulated in the reference period (1988-2010) ranges from 600 to $1800 \mathrm{~mm}$ while the observed annual precipitation 
is between 680 and $1640 \mathrm{~mm}$ over the chosen window. The spatial distribution of precipitation is almost similar in the reference period and the scenario period (2028-2050). In the south, a diagonal band of relatively low rainfall ( $<1000 \mathrm{~mm} /$ year) follows the Ghanaian-Togolese coast in relationto the diffluence of the monsoon winds and the seasonal rise of coastal cold water. However, we noted minor discrepancies, especially in the number of rainy days, as shown in Table 2, for METO and SMH. MPI and ICT simulate the same number of rainy days in the reference period and the scenario or projection period. By comparing it to the reference period (1988-2010) data, the models METO and $\mathrm{SMH}$ project a reduction in rainfall amounts during the projection period (2028-2050) by $2 \%$ and $4 \%$, respectively [55]. In contrast, the fifth IPCC assessment reports a slight increase in precipitation over West Africa. Nevertheless, they could not be able to show any trend in precipitation in this zone.
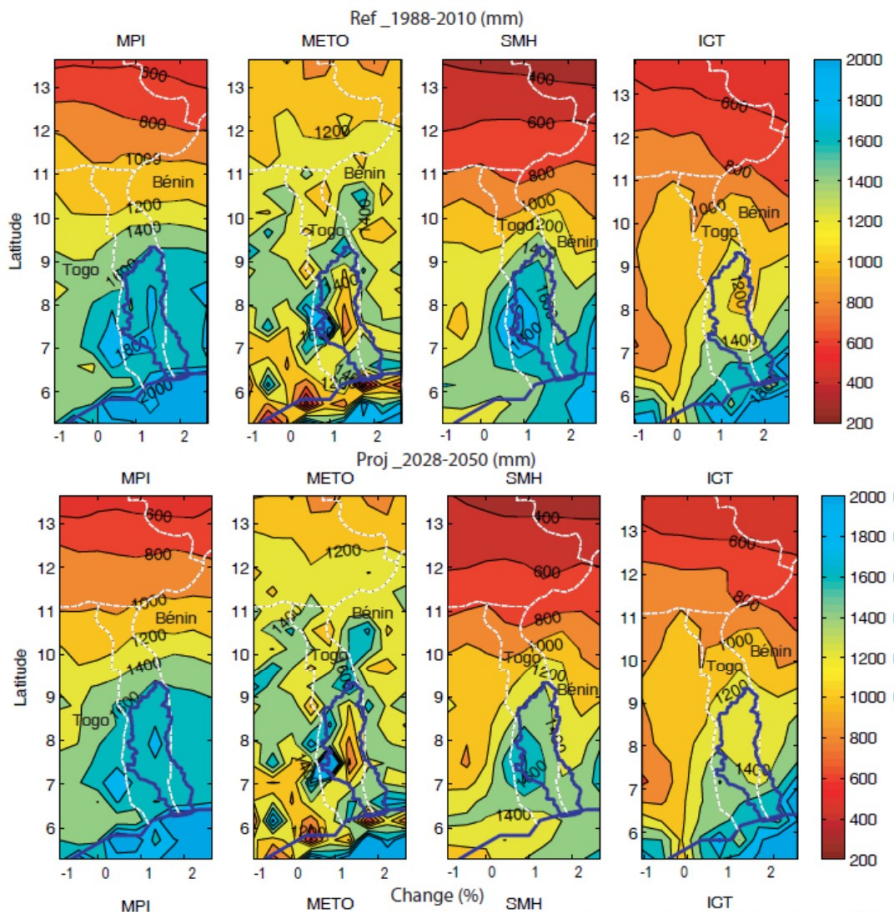

MPI

METO Change (\%)
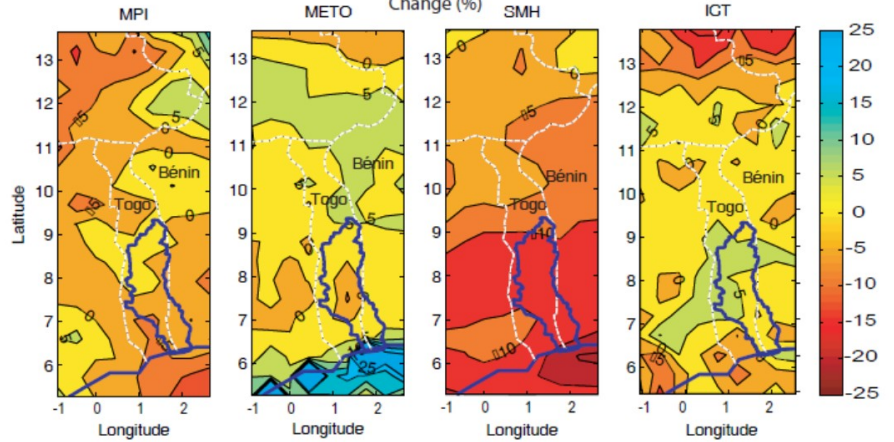

Figure 4. Spatial variation of the mean annual precipitation in the Mono river basin and surrounding areas as modeled by the four Regional Climate Models (RCMs). Upper panels: 1988-2010 reference period; Middle panels: 2028-2050 projection period; Bottom panels: variation between the reference and the scenario periods (\%). 
Table 2. Percentage (\%) of the number of rainy days (>1 mm).

\begin{tabular}{ccc}
\hline RCMs & Ref_1988-2010 & Proj_2028-2050 \\
\hline MPI & 42 & 42 \\
METO & 63 & 62 \\
SMH & 47 & 45 \\
ICT & 48 & 48 \\
\hline
\end{tabular}

An analysis of the variations between the two periods shows moderate but contrasting changes from one model to the others, and across the domain. METO and ICT have projected a slight increase in rainfall ranging between $2 \%$ and $5 \%$ by 2050 . Meanwhile, MPI projection shows no rainfall change whereas SMH has projected a strong rainfall deficit amounting up to $15 \%$ to $20 \%$ by 2050 in the south of the Mono river basin. These precipitation changes are associated with an increase in air temperature. This result is in accordance with the IPCC report [55] over the West Africa region. The same conclusion was made by Sylla et al. [59].

Figure 5 shows for the Mono river basin and surrounding areas, the spatial distribution of the simulated mean air temperature. It came out that the spatial distribution of the mean air temperature is well reproduced by the RCMs although most of these RCMs, especially SMH, underestimate the values. MPI simulates temperature variations closer to the observations and a much better spatial distribution. However, MPI still overestimates the average minimum air temperature (e.g., $27.5^{\circ} \mathrm{C}$ on average for the whole catchment area) compared to the observed data $\left(26.5^{\circ} \mathrm{C}\right)$.

An analysis of Figure 5 for air temperature changes between the projection and reference periods confirms warming of a $1{ }^{\circ} \mathrm{C}$ magnitude order whatever the model. This fairly corroborates the $1.22{ }^{\circ} \mathrm{C}$ temperature increase obtained with the historical data and is also in good agreement with the SRES-A1B scenario. METO is the only RCM that projected a warming of more than $1.5{ }^{\circ} \mathrm{C}$ by 2050 all over the region, except on the coast of the Gulf of Guinea. Thus, the control of the large-scale driver is key to reproducing an accurate simulation of these dry zone features whose origin is mainly related to ocean-atmosphere interactions along the Ghana-Togo coast [60]. This finding agrees with some previous studies in West Africa. For instance, Sylla et al. [59] reported a gradual warming spatial variable reaching $0.5^{\circ} \mathrm{C}$ per decade in recent years over West Africa, with a recovery from drought conditions. However, the amount of total annual precipitation of this recent decade is still lower compared with the decade before the 1970s' and 1980s' drought episodes [61,62]. Moreover, they also confirmed the increasing trend in the projected air temperature, and this could be in the range of 1.5 to $6.5^{\circ} \mathrm{C}$ depending on the emission scenario. Furthermore, the projection of precipitation is with a lot of uncertainties. The West Africa region could experience change in the range of $\pm 30 \%$ in the future associated with more intense extremes in the future climate but to a lesser extent [55,59]. 

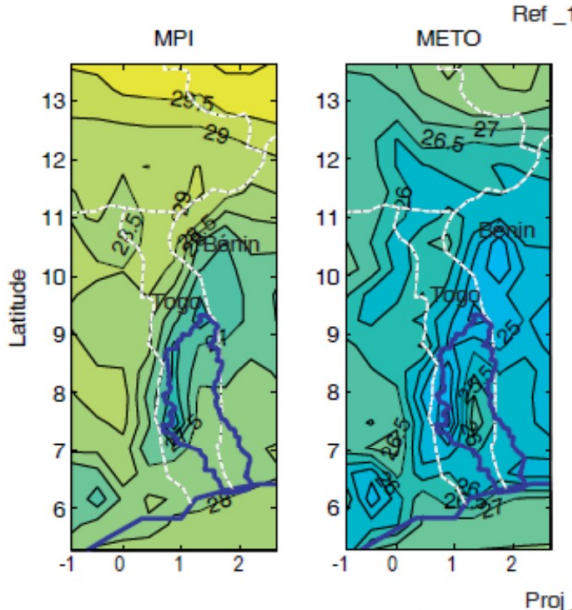

ef _ $1988-2010\left({ }^{\circ} \mathrm{C}\right)$
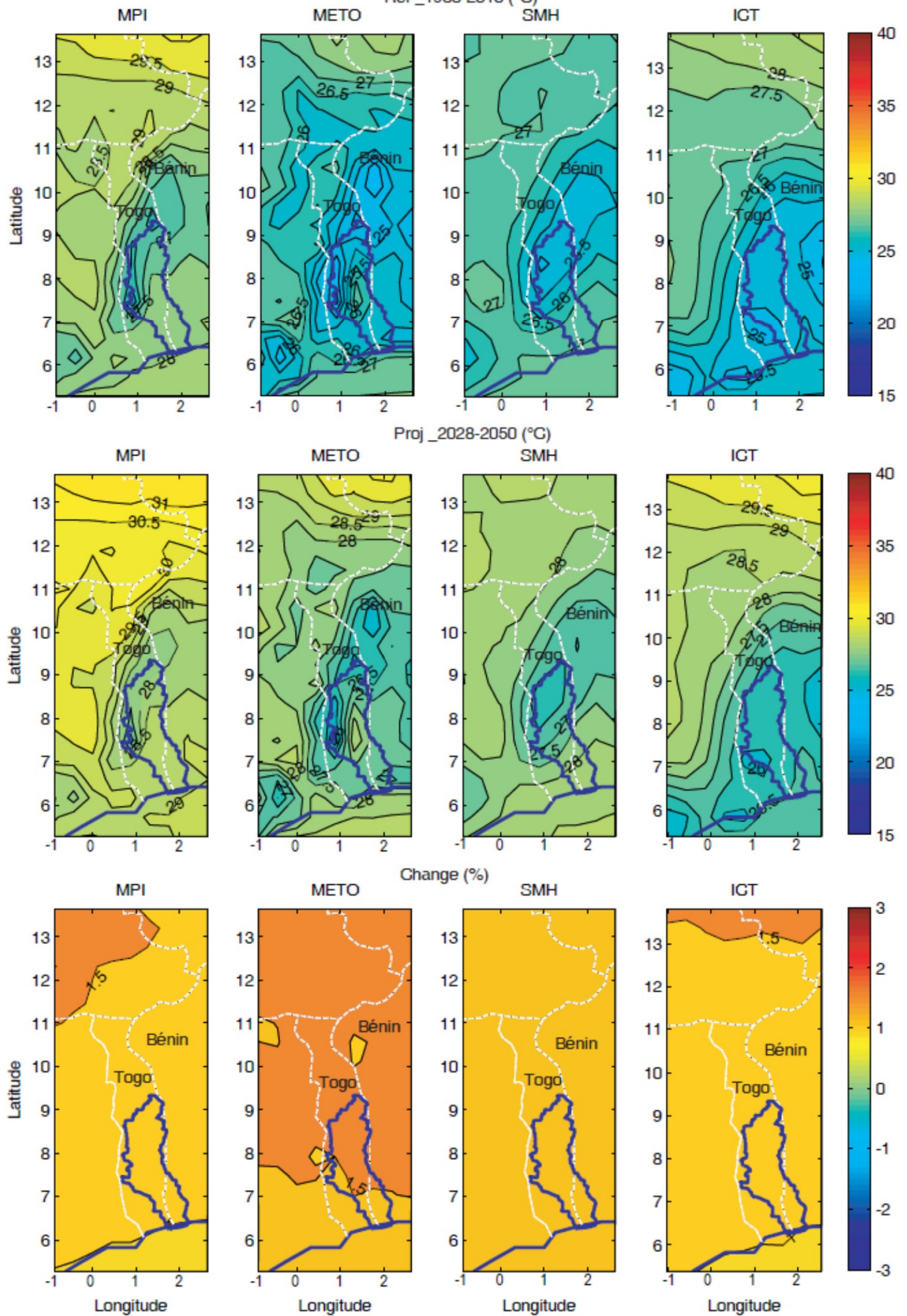

Change (\%) SMH
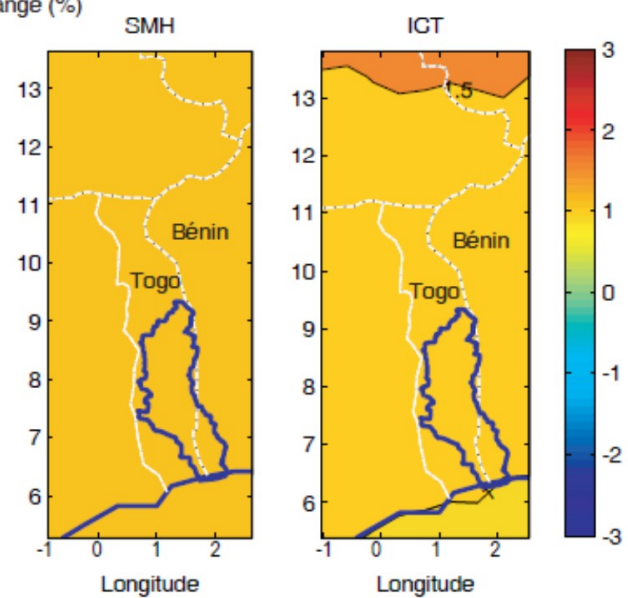

Figure 5. Spatial variation of the annual mean air temperature in the Mono river basin and surrounding areas as simulated by the four RCMs. Up: 1988-2010 reference period (in ${ }^{\circ} \mathrm{C}$ ); Middle: 2028-2050 projection period (in ${ }^{\circ} \mathrm{C}$ ); Down: variation between the reference and projection periods.

\subsection{Average Rainfall and Temperature Regimes in the Mono River Basin at the Nangbéto Outlet}

Figure 6 shows the average rainfall and air temperature regimes in the Mono river basin upstream of Nangbéto as obseved and modeled by the four RCMs. 

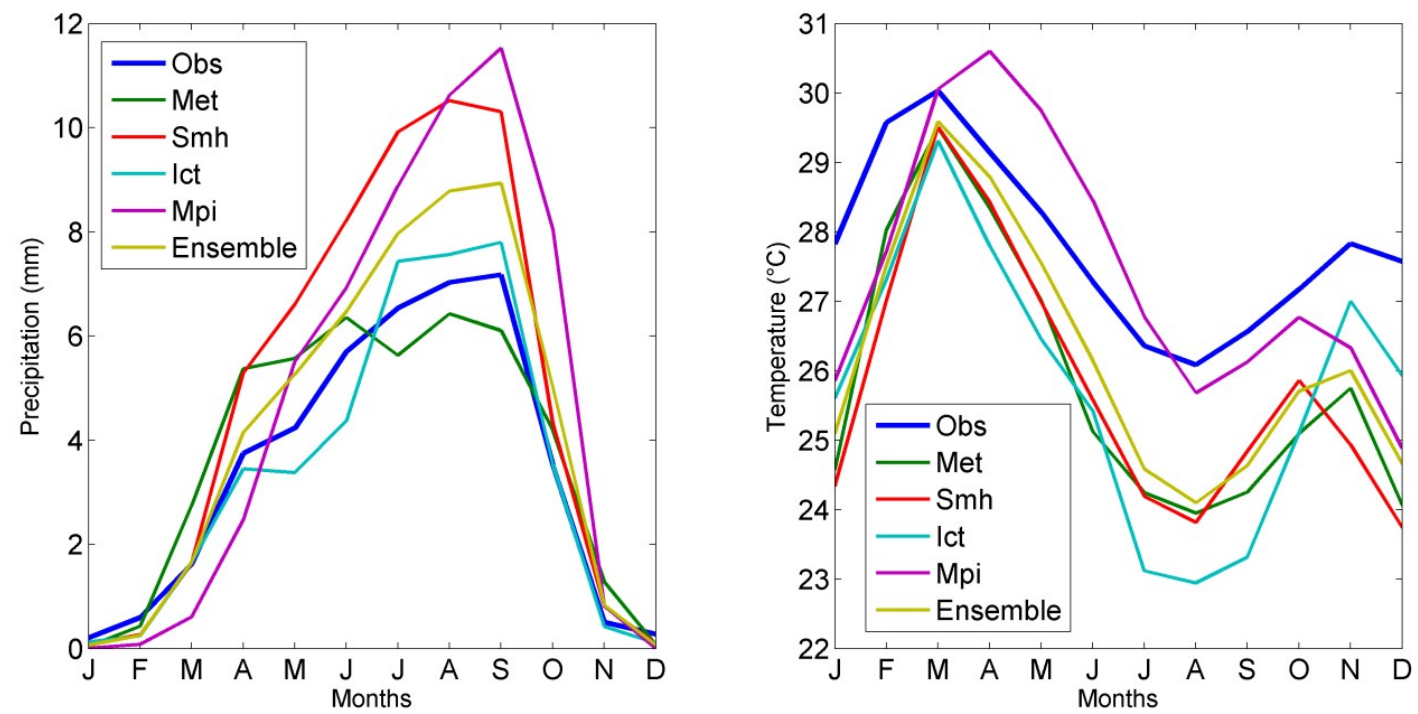

Figure 6. Comparison of the observed and simulated rainfall $\left(\mathrm{mm} /\right.$ day) and air temperature $\left({ }^{\circ} \mathrm{C}\right)$ regimes in the Mono river basin at the Nangbéto outlet (1988-2010 average).

As shown in Figure 6, the four RCMs reproduce the seasonal cycle of precipitation well. This has been proven earlier by some previous works in the region $[54,57,63]$. In the middle of the rainy season, MPI, SMH, and ICT overestimated the rainfall amounts while they also underestimated the rainfall amounts in January-February, which corresponds to the dry season. The smallest biases were obtained with ICT, thus making ICT the model that best replicated the rainfall regime of this watershed.

In most cases, the RCMs satisfactorily reproduce the temperature seasonality in the watershed. The simulated temperature values are underestimated, except MPI, which overestimates these values from April to July. These biases can significantly influence hydrological impact simulations as they will lead to an under(over)estimation of the high streamflow because of an under(over)estimation of the evaporative loss.

Figure 7 reveals the annual cycle of precipitation simulated by the RCMs for the reference period (1988-2010) and the projection period (2028-2050). For SMH, a moderate decrease in the rainfall regime is shown, especially from March to September. SMH fails to reproduce the observed rainfall regime. The other RCMs rarely show a significant decrease, except METO from June to August. A Fisher's test indicates that the changes of the rainfall regime between the reference and projection periods are not statistically significant at a $95 \%$ confidence level. Therefore, we assume that only small changes are to be expected in the hydrological regimes by 2050 . 

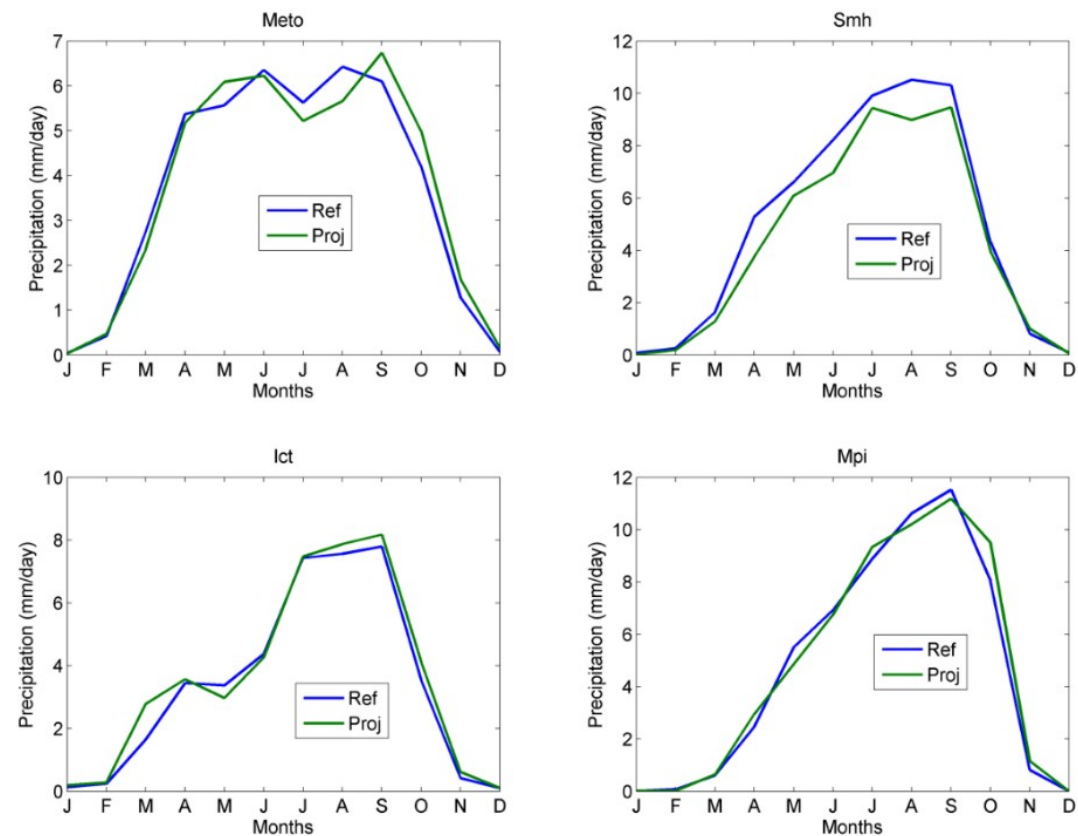

Figure 7. Regional climate models (RCMs) projection of monthly average precipitation (mm/day, 2028-2050) and comparison to the reference period (1988-2010).

Figure 8 reveals that the four RCMs projected an increase of the air temperature by 2050 . This could amplify the evaporative loss in the future and potentially induce a decrease in surface runoff. This warming is relatively uniform throughout the year and ranges between +1 and $+1.5^{\circ} \mathrm{C}$ (a little beyond this range for METO) in accordance with some previous studies [55,59].
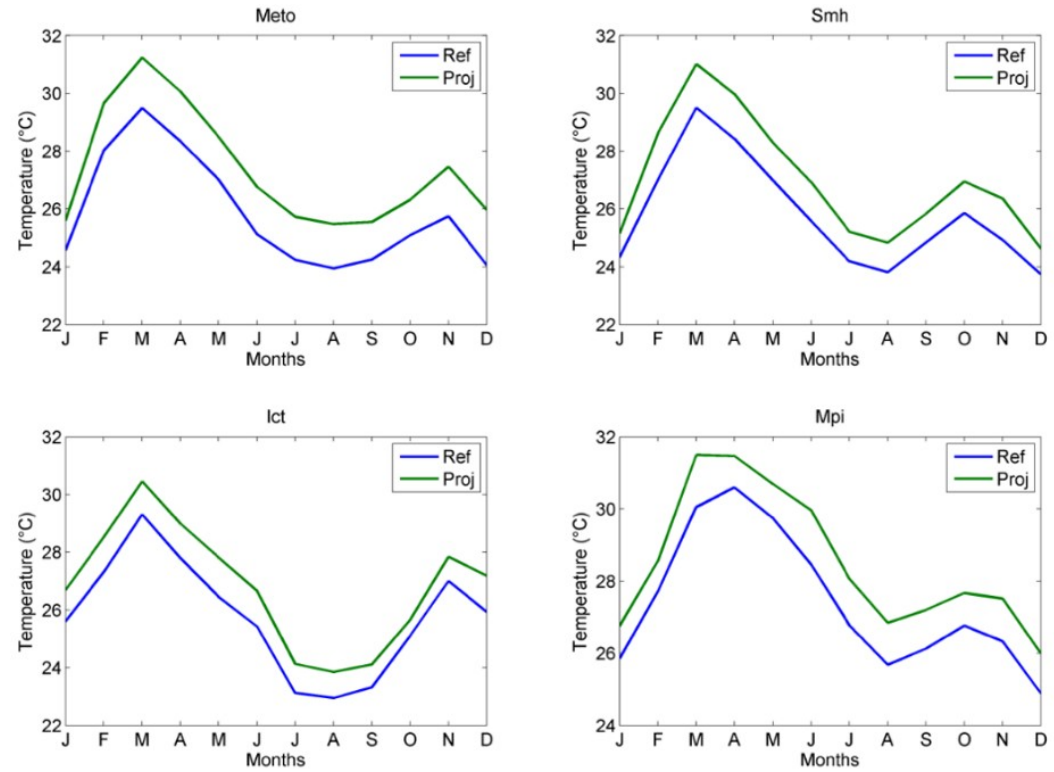

Figure 8. Projection of the monthly near-surface mean air temperature (2028-2050) and comparison to the reference period (1988-2010) for the four RCMs.

Overall, there is a good fit between the seasonal cycles of precipitation and air temperature simulated by the four RCMs, but some of these models still feature biases. The precipitation biases are more dependent on the RCM than the driving GCM. Sylla et al. made the same conclusion $[54,59]$ over West Africa. Indeed, the strongest overestimations of rainfall during the monsoon seasons were obtained with the MPI and SMH experiments. These RCMs were not driven by the same GCM 
(ECHAM5 for MPI and HadCM3 for SMH). In addition, both ICT and MPI are forced by ECHAM5 but the ICT simulates a more realistic annual precipitation cycle than MPI. Thus, the projection biases originate from both the RCMs and their driven GCMs.

\subsection{Frequency Analysis of Rainfall Distribution in the Mono River Basin}

The cumulative frequency of daily rainfall intensity according to the four RCMs is illustrated in Figure 9. This figure compares the distributions of rainfall intensity between observations and the RCM simulations in the reference period, and between the RCM simulations in the reference and projection periods. For most RCMs, the sill of the cumulative daily distribution is obtained after 200 days, except METO, for which the sill is obtained after 250 days. For SMH and ICT, the distribution of daily rainfall frequencies agreed well with the observations, with many days recording less than $20 \mathrm{~mm}$, and a number of wet days (about 200) similar to the observations. METO shows many wet days with a very high number of medium intensity days $(5-10 \mathrm{~mm})$. By contrast, the MPI model underestimates precipitation occurrence, especially for intensity values around 5 to $15 \mathrm{~mm} /$ day. The study of Tossou et al. [64] also provides a characterization and analysis of rainfall variability in the Mono river watershed complex.
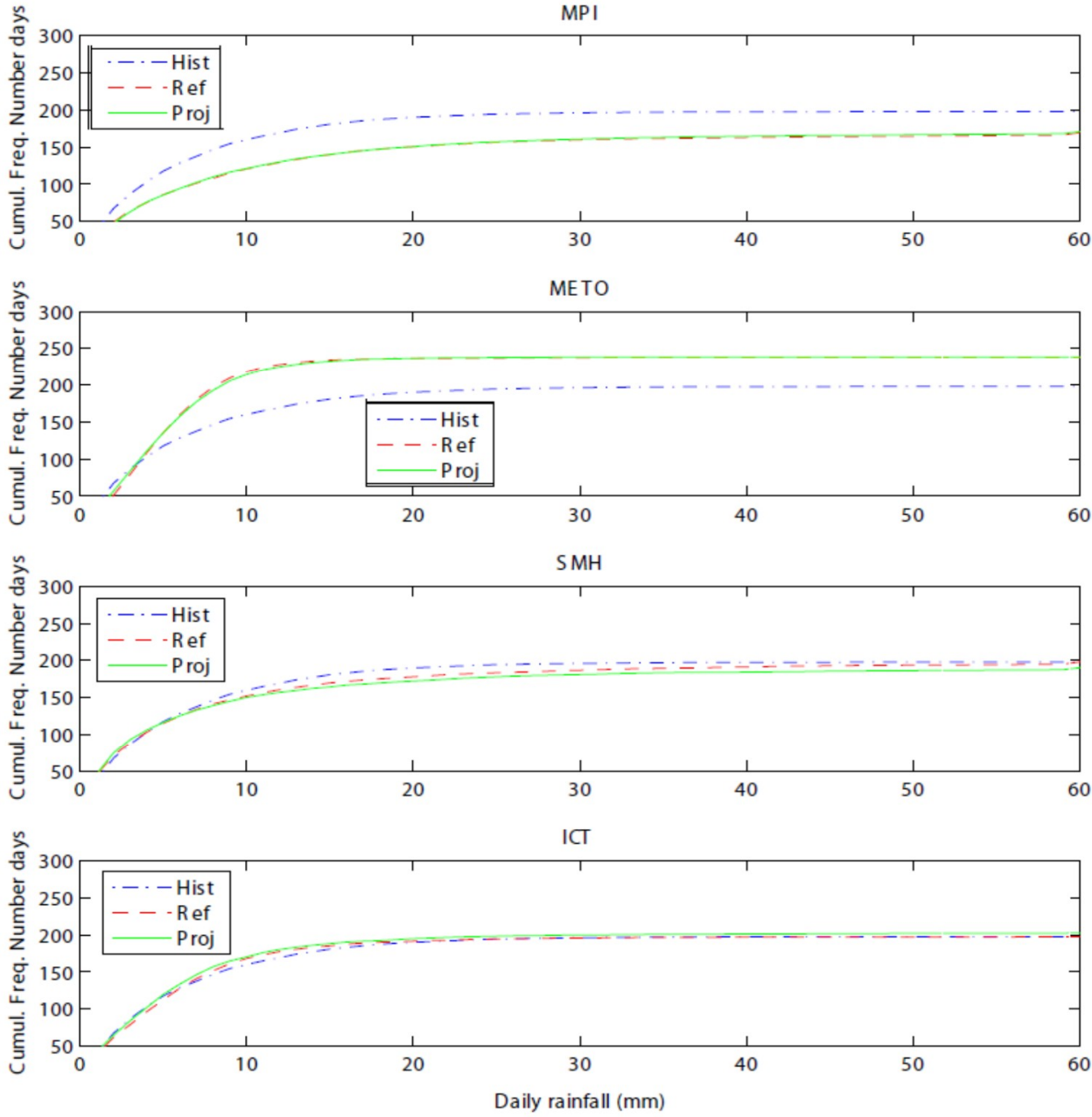

Figure 9. Cumulative distributions of daily precipitation from the four RCMs and comparison to observations (interpolated rainfall field). Cumul. Freq. Number Days = cumulative frequency of the number of days. NB: The empirical cumulative frequency of the number of rainfall days consists of adding up the sum of the number of days with more than $1 \mathrm{~mm}$ of rain. 
In the projection period, the four RCMs projected a similar distribution of precipitation in the study area as in the reference period, except the SMH model, for which a small change in the distribution of precipitation is displayed, i.e., a slightly reduced number of rain days beyond $10 \mathrm{~mm}$. This close relationship between the distributions from simulations and observations is consistent with previous findings $[3,21,27,46,65,66]$ and confirms that the RCMs satisfactorily reproduced rainfall at a local scale as stated by Amoussou [2] and other works [4,6,67].

A detailed analysis was performed to overcome the bias challenges regarding the number of rainy days and to better describe the future changes in rainfall distribution. We computed the deciles of the observed daily rainfall and examined for each RCM the contribution of these 10 rainfall classes to the total rainfall as shown by López-Moreno and Beniston [27] in their study on the evolution of rainfall intensity in the Pyrenees. The computation was made for both the reference period (1988-2010) and the projection period (2028-2050). This approach helps to quantify the evolution of the influence of precipitation belonging to different classes of the frequency distribution [27,68-71].

Figure 10 displays for the Mono river basin at the outlet of Nangbéto the rainfall distribution from the four RCMs according to the thresholds of the 10 quantiles as obtained from the observations. The threshold values are provided at the bottom of Figure 10.
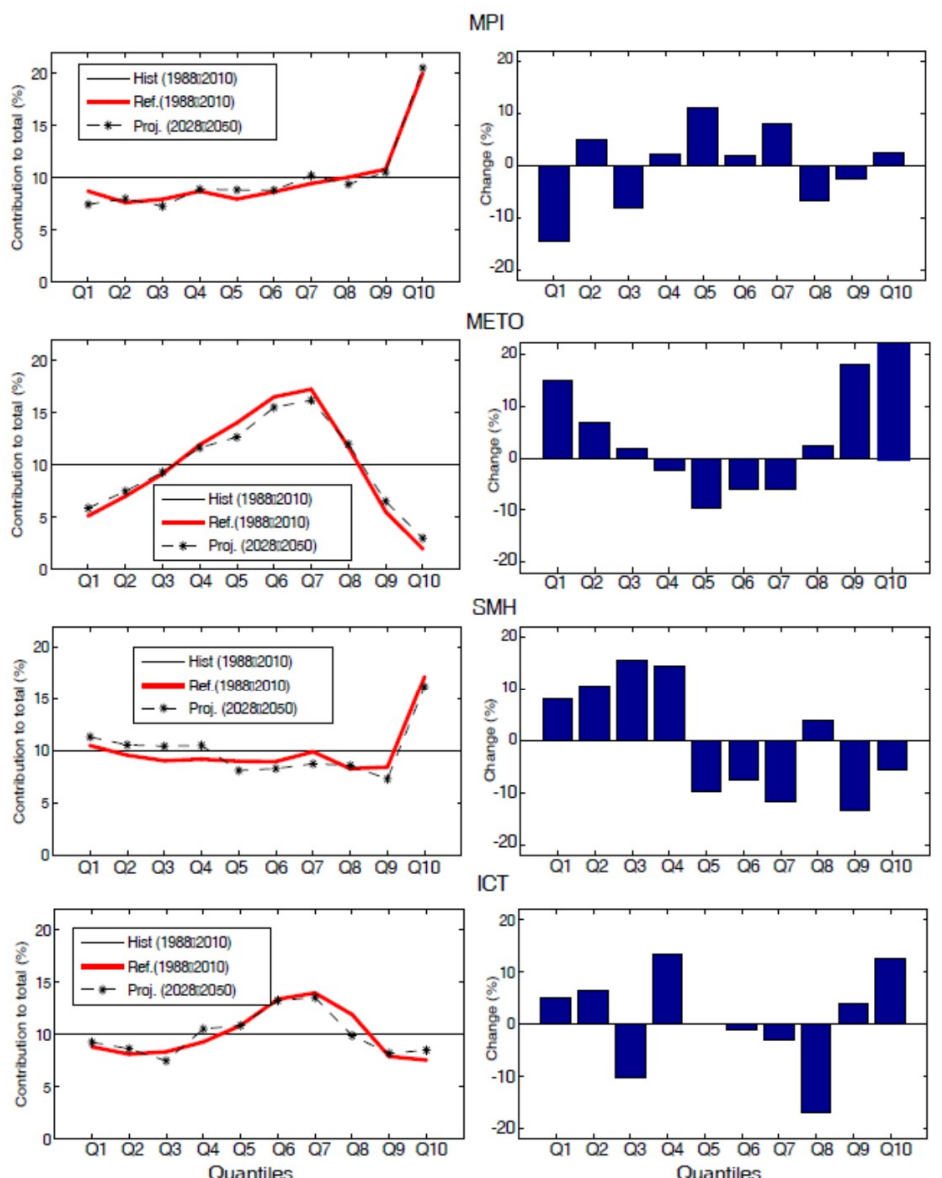

Quantiles Quantiles

\begin{tabular}{|c|c|}
\hline \multicolumn{2}{|l|}{ Thresholds of } \\
\hline $1.00<Q<1.49$ & $4.88<06<6.33$ \\
\hline $1.49<\mathrm{O} 2<2.10$ & $6.33<07<8.33$ \\
\hline $2.10<03<2.80$ & $8.33<08<10.95$ \\
\hline $2.80<04<3.76$ & $10.95<09<15.17$ \\
\hline $3.76<05<4.88$ & Q10: >15.17 \\
\hline
\end{tabular}

Figure 10. Comparison of the contribution of the 10 classes of quantile of daily precipitation defined from observations (interpolated rainfall field) to total precipitation under present-day and future climates (SRES-A1B scenario) (left), and changes between the reference and projection periods (right). 
Figure 10 indicates that apart from $\mathrm{SMH}$, all RCMs underestimate the distribution of rainfall quantiles, especially the contribution of low rainfall (first four quantiles). This reveals an underestimation of the frequency of low rainfall. For the fifth decile to the eighth decile, the MPI and SMH simulations are close to the observed values. Meanwhile, both ICT and METO overestimate the rainfall in the basin, but this overestimation is stronger with METO. ICT and METO also underestimate the heavy rains (Q9 and Q10), unlike SMH and MPI, which simulate an increase of the daily rainfall (Q10) in the Mono river basin. Between the projection period (2028-2050) and the reference period (1988-2010), the analysis shows a relatively stable distribution of rainfall for most rainfall quantiles from MPI and ICT. For SMH, a strong decrease is found in the contribution of rainfall from the fifth quantile. Meanwhile, an increase of the contribution of the high rainfall intensities to the total rainfall is expected with METO.

\subsection{Analysis of Extreme Precipitation under Present Day and Future Climates}

The hydrological and societal importance of high-intensity rainfall coupled with the disparities between the RCMs regarding the reproduction of the 10th decile of daily rainfall (Q10 $>15 \mathrm{~mm}$ ) led us to investigate the 99th percentile of daily rainfall in order to better understand the dynamics of heavy rainfall in the Mono river basin. We also analyzed the 5-day cumulative rainfall that likely contributes to flood generation downstream of the basin. Recurrent flood events were experienced in recent years in the Mono river basin [40] because of the high risk of soil saturation that induces a fast runoff. Table 3 displays the 99th percentile of precipitation for the reference and projection periods (1988-2010 and 2028-2050).

Table 3. 99th percentile values of daily precipitation in the Mono river basin.

\begin{tabular}{|c|c|c|c|c|c|}
\hline Precipitation (mm) & Hist & MPI & METO & SMH & ICT \\
\hline \multicolumn{6}{|c|}{ Ref_1988-2010 } \\
\hline 99th percentile & 29.92 & 86.66 & 17.98 & 75.22 & 31.32 \\
\hline \multicolumn{6}{|c|}{ Proj_2028-2050 } \\
\hline 99th percentile & - & 85.70 & 19.36 & 71.39 & 38.11 \\
\hline
\end{tabular}

The values in Table 3 show that in the reference period, about $30 \mathrm{~mm} /$ day of rainfall is equivalent to the 99th percentile in this basin, i.e., the highest $1 \%$ of the precipitation days according to the historical data. This recorded heavy rainfall intensity followed or preceded by rainy days could trigger catastrophic floods in the Mono river basin.

ICT simulation of heavy rainfall is the closest to observations. METO underestimated the heavy rainfall whereas SMH and MPI largely overestimated these rainfall extremes. A 99th percentile greater than $75 \mathrm{~mm} /$ day is too high for a catchment of $15,680 \mathrm{~km}^{2}$. However, this is not excluded because the rainfall of a year can precipitate in almost a day, as was the case in Ouagadougou (Burkina-Faso) in 2009 with nearly $290 \mathrm{~mm}$.

In simulation as in projection, the ICT model simulates the heavy rains, but MPI and SMH overestimate them while the low rains are recorded by METO. With the reference data used, the MPI model especially simulates the very heavy rainfall the best, as well as projection periods. In both the reference and projection periods, the evolution is almost identical whatever the climate model [72,73].

In order to comprehend the seasonal distribution of these heavy rains, we also computed per month the 99th percentile of daily rainfall (Figure 11). 

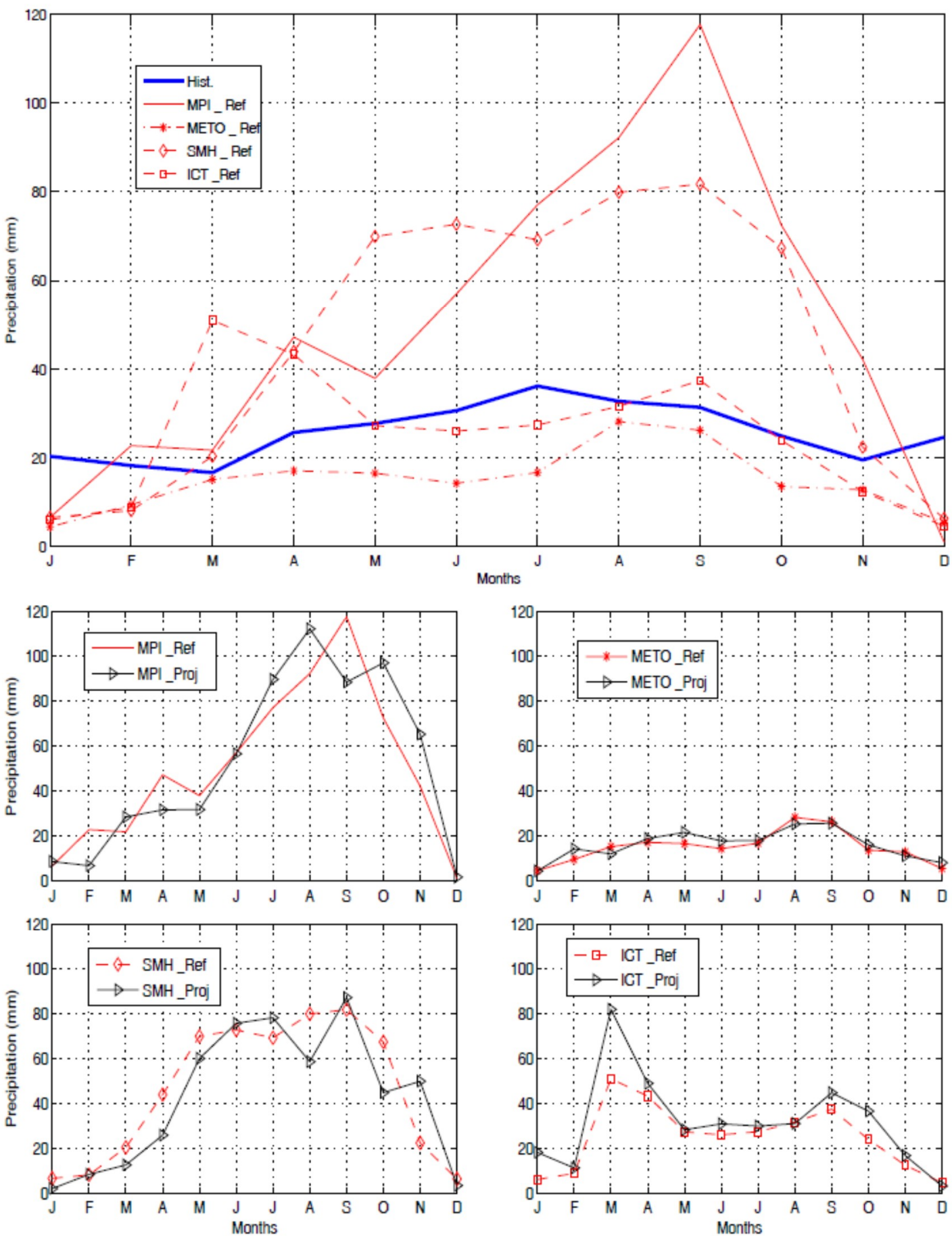

Figure 11. Monthly variation of the 99th percentiles of daily precipitation in the Mono river basin. Top panel: comparison between observation and simulation during the reference period. Bottom panels: comparison between the reference and the projection periods.

The distribution of the 99th percentiles of daily rainfall shows that all RCMs underestimated the heavy rainfall from November to February (dry season). However, MPI overestimated the heavy rainfall in February and November while SMH overestimated only that of November in the dry season. The high rainfall observed in December and January is only sporadic because the occurrence of rainfall events during the dry season is extremely rare. SMH and MPI also overestimated the rainfall intensity in the core rainy season months (a maximum of $65 \mathrm{~mm}$ in September for MPI). This hinders a realistic estimation of the hydrological risks. 
In the projection period, we will focus on ICT simulations and to a lesser extent on METO simulations as these two climate models stand out as being the most realistic for simulating heavy rainfall events in the basin. For these two climate models, the heavy rainfall intensities obtained in the projection period are close to those of the reference period even if an increase is noticeable in many months. ICT shows a sharp one-off increase of rainfall intensity in March. However, SMH and MPI predicted a slight decrease in the intensity of the heavy rainfall events from February to August and from August to October, respectively, but these two climate models are the least realistic for the simulation of the heavy rainfall intensities.

The monthly variation of the 99th percentile rainfall maxima shows that the most intense heavy rainfall events occur at the core of the rainy season. However, the so-called dry months sometimes record strong rainfall. Therefore, an analysis of the return periods of the heavy rainfall events can help to better understand the distribution and occurrence of the extreme events in the Mono river basin, and the occurrence of high streamflow in the basin upstream of the dam, and the resulting floods. This result agrees with the study of Kodja [74] in tthe Ouémé river basin, which is located in the same climatic zone as our study basin.

\subsection{Analysis of the Return Periods of Rainfall Extreme Using a GEV Model}

The annual maxima of daily rainfall in the Mono river basin upstream of the outlet of Nangbéto (observed and simulated values) were adjusted to a generalized extreme value (GEV) distribution. The values of the three parameters, namely k, sigma $(\varsigma)$, and $\mathrm{mu}(\mu))$ of the GEV distribution (Figure 12), show a similarity between the observed and simulated data for the sigma and mu parameters but strong differences for the $\mathrm{k}$ parameter, where $\mathrm{K}$ refers to the shape parameter, sigma the scale parameter, and $\mathrm{mu}$ stands for the location parameter [75]. Nevertheless, these three parameters were always positive (for observations and simulations in the reference and projection periods) (Figure 12), thus pointing to a Frechet distribution (extreme value distribution type II).

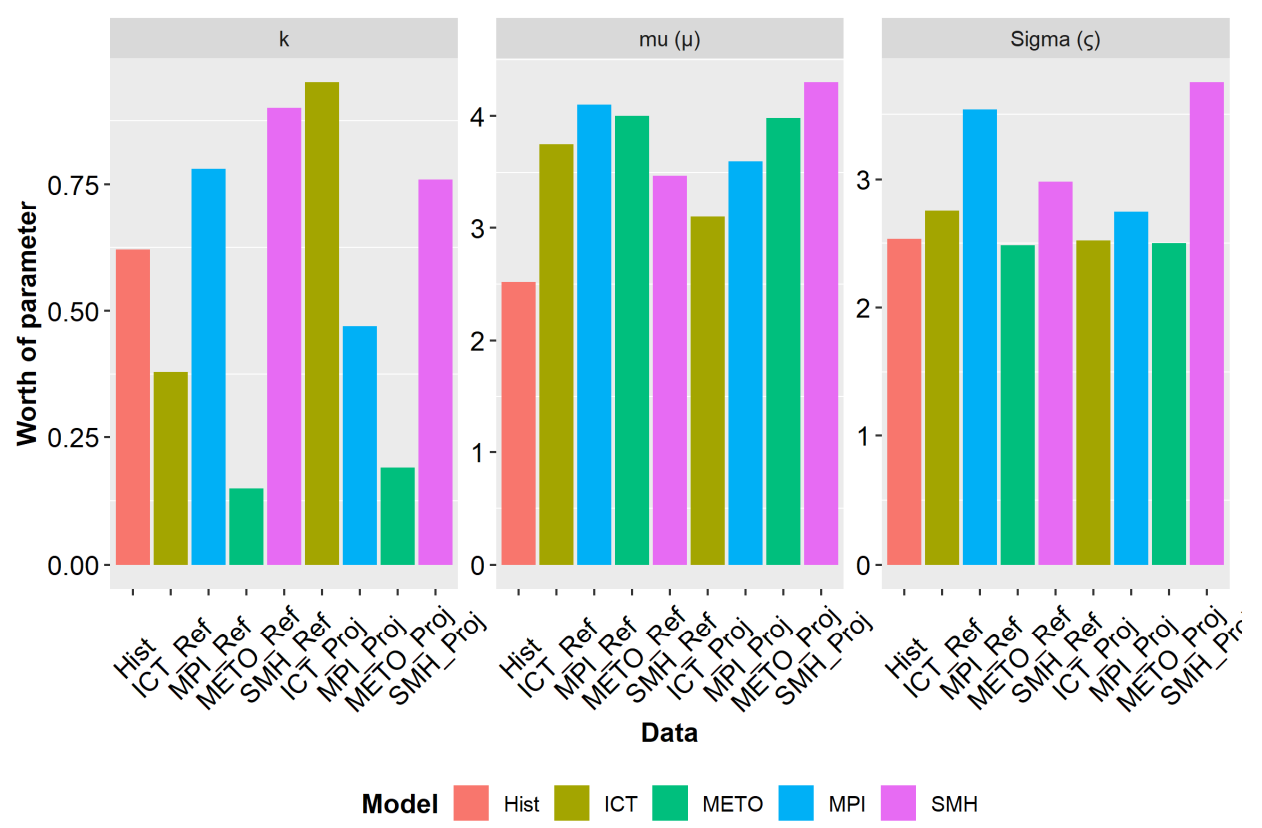

Figure 12. Temporal evolution of the three parameters (k, sigma, mu) of the Generalized Extreme Value (GEV) distribution for different sets of data.

Furthermore, when $\mathrm{k}>0$, the GEV distribution is the type II, or Frechet, extreme value distribution. The variance of GEV is not finite when $k \geq 1 / 2$. The GEV distribution has positive density only for values of $X$, such that $k \times(X-m u) /$ sigma $>-1[75]$. 
Figure 13 shows the evolution of the annual maxima of observed daily rainfall. The analysis reveals a strong increase in the annual maximum of daily precipitation that is statistically significant at the $95 \%$ confidence level. The frequency of high streamflow is not increasing, and this could be explained by the increase in temperature, which induces more evapotranspiration and thus compensates for the impact on high streamflow. This has also been proved by Ntajal et al. [49] downstream of the Mono river basin. However, an in-depth analysis is still needed to prove this assumption because, in principle, very high streamflow is sometimes generated from rapid runoff in response to water excess in soil with a low retention capacity $[41,71,76]$. This occurs in a very short time period, during which the increase of the evaporative demand is not really a constraint.

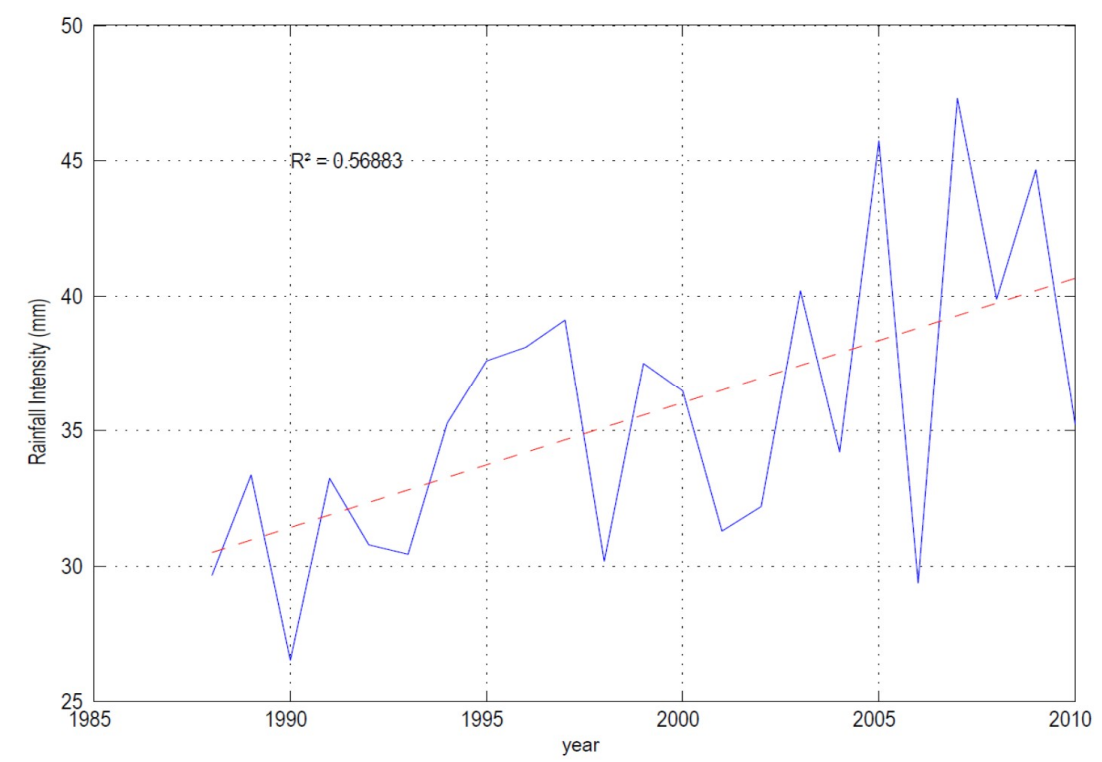

Figure 13. Interannual variation of the daily rainfall maxima from 1988 to 2010 in the Mono river basin at the outlet of Nangbéto.

This result is consistent with the evolution of discharge maxima flowing into the Nangbéto dam from 1988 to 2010, which pointed to an increase of the annual maxima, which is significant at $p=0.0185$ according to a Mann-Kendall test $[41,77,78]$.

Figure 14 compares the distributions of the quantiles of daily rainfall maxima observed over 23 years (1988-2010) to those adjusted by the GEV.

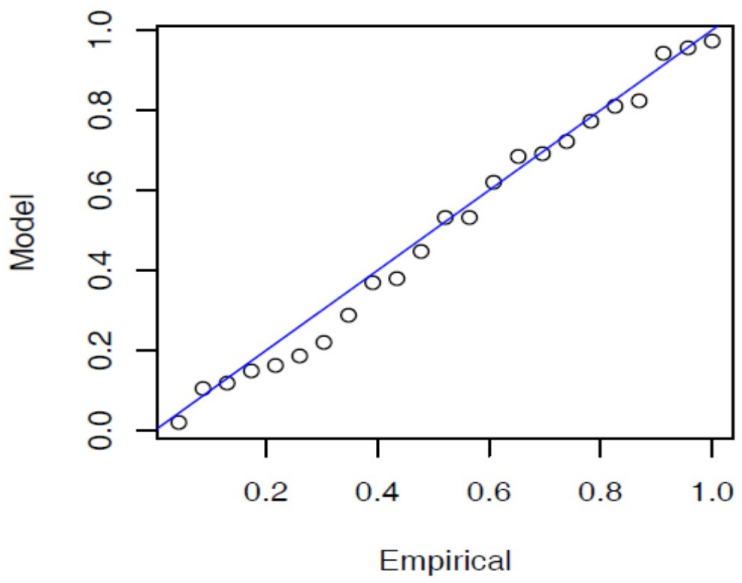

Figure 14. Comparison of the annual maxima of the quantiles of observed and simulated rainfall with a GEV model. 
The annual maxima of daily rainfall are well adjusted to the GEV distribution. The analysis of the return periods of the extreme rainfall events, as displayed in Figure 15, shows that the rainfall events of an intensity higher than $40 \mathrm{~mm}$ are likely to occur at a recurrence interval of about 5 years.

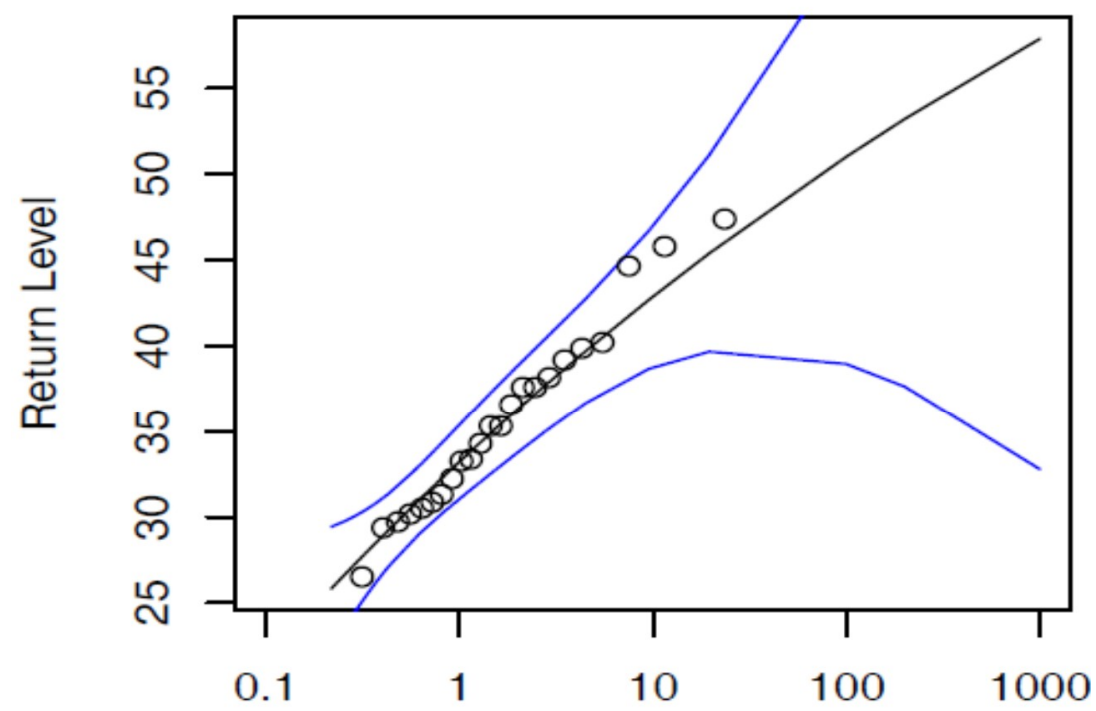

Return Period

Figure 15. Estimation of the return periods of the annual maxima of rainfall events ( $\mathrm{mm})$. The circle represents the observed values over 23 years (1988-2010) and the blue curves refer to the confidence level.

The uncertainty of the rainfall events occurring in a 50-year recurrence interval is higher because of the short length of the available time series and the trend shown in Figure 13.

Table 4 presents the return periods for the annual maxima of the daily rainfall simulated with ICT, which stands out as the best of the four models for the reproduction of intense rainfall. The rarest and thus most intense rainfall events remain poorly simulated, as illustrated by the divergence of the 10-day recurrence values ( $45 \mathrm{~mm}$ in the observations, $77 \mathrm{~mm}$ in the model). Nevertheless, the projections show a strong increase in rainfall intensities for all return periods described in Table 4 . The daily precipitation increases with the return period in the basin, which is in accordance with Ntajal et al.'s [49] and Kodja's [74] studies in the Mono and Ouémé basins, respectively. Ntajal et al. [49] compared the return period at the annual time scale and showed that GEV gives overestimation than the Goodrich exponential distribution model. This could also justify the overestimation of the model.

Table 4. Annual daily precipitation ( $\mathrm{mm}$ ) for different return periods in the Mono river basin.

\begin{tabular}{cccc}
\hline Return Periods (Years) & Hist & ICT_Ref & ICT_Proj \\
\hline 1 & 32.5 & 40 & 90 \\
2 & 35 & 48 & 100 \\
5 & 40 & 52.5 & 120 \\
10 & 45 & 77 & 200 \\
20 & 47.5 & 89 & 289 \\
\hline
\end{tabular}

This could induce high magnitude floods, which may pose a critical risk of flood inundation and thus cause damages with severe economic and societal consequences in the lower valley of the Mono river basin. Considering these return periods, the amounts of heavy rains projected are alarming. This confirms the increase in intense rainfall events predicted by the regional climate models. 


\section{Conclusions}

The comparative analysis of different regional climate models simulating air temperature and precipitation in the Mono river basin and the West African sub-region leads to three major conclusions regarding their ability to reproduce the present-day climate.

First, apart from the few exceptions noted below, the realism of the simulated climate is more controlled by the regional climate model (RCM) than the driven global climate model (GCM). For the same forcing GCM (ECHAM5 or HadCM3 in this study), the precipitation fields are substantially different from one RCM to the others used for the dynamical downscaling. This strong model sensitivity may arise from the RCM structure (model approximations) or from the choice of parameterization techniques made to run each model (e.g., convective scheme).

Second, though the seasonal cycles of air temperature and precipitation are well reproduced by the RCMs, most of them still feature systematic errors related to the magnitude of these variations. In general, the selected RCMs underestimate air temperature in the range $1-3{ }^{\circ} \mathrm{C}$ for the Mono river basin. Two RCMs largely overestimate rainfall (by a factor of 1.5 to 2) during the rainy season. This overestimation is due to very high rainfall intensities that could not be compensated by the underestimation of the number of rainy days. The most realistic models regarding the reproduction of the actual seasonal cycle are those that simulate both the frequency of rainfall events and the average intensity of daily rainfall well (ICT and to a lesser extent METO). Finally, almost all RCMs introduced bias with respect to the spatial variation of the climatic variables being analyzed. The north-south gradients of precipitation between the Sahel and the Guinean regions are well reproduced by all RCMs, except METO, although the simulated values for precipitation are not always correct. There are also errors in the southern part of the Guinean region regarding the reproduction of the drought band diagonally stretching from southern Ghana to southern Benin (Dahomey Gap). It was not reproduced by the RCMs forced with ECHAM5 GCM at their boundaries (MPI and ICT).

Third, and this is implicitly derived from the conclusion above, the hierarchy of RCMs in terms of the quality of their simulations differs according to the climate variable considered. For example, MPI tends to offer the most accurate reproduction of air temperature (especially their spatial distribution) and ICT is the most realistic for the precipitation patterns. This conclusion still needs to be taken with caution because though ICT satisfactorily reproduces the rainfall regimes and the frequency distribution of the rainfall events, the spatial distribution of the average annual precipitation is better simulated by the SMH model. Indeed, ICT fails to reproduce the relative dryness of the Ghanaian-Togolese coast in the south of the Guinean region. As well, ICT still features bias regarding the reproduction of the return periods of the annual rainfall maxima, for which it overestimated the frequency despite its good performance for the reproduction of the distribution of daily rainfall. Thus, we conclude that the choice of an appropriate RCM should be based on the research objectives, especially for impact studies.

Though these conclusions call for caution in using climate model simulations to assess future climate change in the sub-region, some lessons can nevertheless be drawn. The four RCMs unanimously project a +1 to $+1.5^{\circ} \mathrm{C}$ temperature increase in the sub-region by 2028-2050 as compared to the 1988-2010 reference period. The projected trends for cumulated precipitation are null or very moderate and diverge from one RCM to the others. Only SMH projected a significant decrease of precipitation in the Mono river basin. The simulations of the intense rainfall events (99th percentiles) also display contrasted results, but the two regional climate models that better reproduce these extreme rainfall events in the reference period have also unanimously projected a significant increase in their intensity by 2028-2050.

For the intense rainfall events, the Mono river basin at the outlet of Nangbéto recorded between 1988 and 2010 a significant increase in the intensity of the maximum daily rainfall averaged over the watershed, and this increase may be a risk factor. The heaviest rainfall events (99th percentile) occur mainly during the months of July to September, with a peak in September. This fits well with the discharge peaks in the basin. Thus, the intense rainfall events recorded in the tropical domain of the 
basin could lead to probable risks of flood inundations in the lower valley of the Mono river basin due to an overflow of the river.

The ICT simulations were the closest to the observations in terms of the reproduction of the cumulated precipitation and frequency distribution of daily rainfall. ICT is thus more robust for the analysis of the intense rainfall events and thereby flood forecasting in the Mono river basin. The estimation of extreme rainfall events using ICT showed stability except for the rainfall events occurring in October-November, which slightly increase. The adjusted GEV model satisfactorily predicted the heavy rainfall events, but there are uncertainties beyond the 90th percentile. The adjustment of a Weibull-type GEV distribution is well suited here for the prediction of extreme rainfall events (shape parameter of the GEV distribution $=0$ ), although it is heavy-tailed at the 99th percentile.

The annual maxima of daily precipitation are increasing. Therefore, the impact of heavy rainfall events on discharge will increase under climate change conditions. This knowledge is important to develop an early warning system for the Mono river basin for the sustainability of the ecosystems. This calls for further research to better understand the physical mechanisms underlying the changes in extreme precipitation events and thus improve climate model simulations for short- and medium-term use. Moreover, for future study, a bias correction could be done for those datasets before quantifying the magnitudes of changes due to their coarser resolution.

Author Contributions: E.A. conducted this research. Conceptualization: E.A., A.D., H.A., S.O., P.C. and H.S.T.V.; Methodology and modelling and data processing: E.A., H.A., H.S.T.V., A.D., K.K.; Writing-Original Draft Preparation, E.A., H.A., H.S.T.V., S.O., A.D., M.B., G.M., C.H.; Writing-Review and Editing, P.C., G.M., C.H. All authors have read and agreed to the published version of the manuscript.

Funding: The APC was funded by les universités des auteurs ayant contribué à la reduction des coûts de publications.

Acknowledgments: The authors thank the reviewers for their comments which improve the quality of the manuscript. We thank the Climatology Research Center (CRC) of Dijon (France) for providing us AMMA-Ensemble data. We thank LAPA-MF -African Centre of Excellence on Climate Change, Biodiversity and Sustainable Development, the Institute of Research for Development (IRD, France) and Institute of Geosciences for Environment (IGE, University Grenoble Alpes) for providing the facility (the Regional Climate Modelling Platform) to perform this study at the University Félix Houphouët Boigny (Abidjan, Côte d'Ivoire).

Conflicts of Interest: The authors declare no conflict of interest.

\section{References}

1. Brown, O.L.I.; Hammill, A.; Mcleman, R. Climate change as the 'new' security threat: Implications for Africa. Int. Aff. 2007, 83, 1141-1154. [CrossRef]

2. Amoussou, E. Variabilité Pluviométrique et Dynamique Hydro-Sédimentaire du Bassin Versant du Complexe Fluvio-Lagunaire Mono-Ahémé-Couffo (Afrique de l'ouest). Ph.D. Thesis, Université de Bourgogne, Dijon, France, January 2010.

3. Mladjic, B.; Sushama, L.; Khaliq, M.N.; Laprise, R.; Caya, D.; Roy, R. Canadian RCM projected changes to extreme precipitation characteristics over Canada. J. Clim. 2011, 24, 2565-2584. [CrossRef]

4. Tramblay, Y.; Amoussou, E.; Dorigo, W.; Mahé, G. Flood risk under future climate in data sparse regions: Linking extreme value models and flood generating processes. J. Hydrol. 2014, 519, 549-558. [CrossRef]

5. Dilley, M.; Chen, R.S.; Deichmann, U.; Lerner-Lam, A.L.; Arnold, M. Natural Disaster Hotspots: A Global Risk Analysis; World Bank: Washington, DC, USA, 2005; Volume 7.

6. Crétat, J.; Vizy, E.K.; Cook, K.H. How well are daily intense rainfall events captured by current climate models over Africa? Clim. Dyn. 2014, 42, 2691-2711. [CrossRef]

7. Panthou, G.; Lebel, T.; Vischel, T.; Quantin, G.; Sane, Y.; Ba, A.; Ndiaye, O.; Diongue-Niang, A.; Diopkane, M. Rainfall intensification in tropical semi-arid regions: The Sahelian case Rainfall intensification in tropical semi-arid regions: The Sahelian case. Environ. Res. Letts. 2018, 13, 064013. [CrossRef] 
8. Niasse, M.; Coalition, I.L. Climate-Induced Water Conflict Risks in West Africa: Recognizing and Coping with Increasing Climate Impacts on Shared Watercourses. In Human Security and Climate Change; PRIO, CICERO and GECHS: Asker, Norway, 2005; pp. 21-23. Available online: https://www.researchgate.net/profile/Madiodio_Niasse/publication/237699436_Climate-Induced_Water_ Conflict_Risks_in_West_Africa_Recognizing_and_Coping_with_Increasing_Climate_Impacts_on_Shared_ Watercourses/links/5440fe550cf2a76a3cc60e7c.pdf (accessed on 1 January 2019).

9. Loughlin, J.O.; Witmer, F.D.W.; Linke, A.M.; Laing, A.; Gettelman, A.; Dudhia, J. Climate variability and con fl ict risk in East. Proc. Natl. Acad. Sci. USA 2012, 109, 18344-18349.

10. Brown, O.; Crawford, A. Climate change: A new threat to stability in West Africa? Evidence from Ghana and Burkina Faso Climate change: A new threat to stability in West Africa? Evidence from Ghana and Burkina Faso 1. Afr. Secur. Stud. 2010, 17, 39-57. [CrossRef]

11. Collier, P.; Conway, G.; Venables, T. Climate change and Africa. Oxf. Rev. Econ. Policy 2008, 24, 337-353. [CrossRef]

12. Oyebande, L. Climate Change Impact on Water Resources at the Transboundary Level in West Africa: The Cases of the Senegal, Niger and Volta Basins. Open Hydrol. J. 2013, 4, 163-172. [CrossRef]

13. Barbe, L. Rainfall Variability in West Africa during the Years 1950-1990. J. Clim. 2002, 15, 187-202. [CrossRef]

14. Dezetter, A.; Servat, E.; Paturel, J.E.; Mahé, G.; Dieulin, C. Using general circulation model outputs to assess impacts of climate change on runoff for large hydrological catchments in West Africa Using general circulation model outputs to assess impacts of climate change on runoff for large hydrological catchments. Hydrol. Sci. J. 2009, 6667, 1.

15. Houghton, J.T.; Ding, Y.D.; Griggs, D.J.; Noguer, M.; van der Linden, P.J.; Dai, X.; Maskell, K.; Johnson, C.A. Climate Change 2001: The Scientific Basis; The Press Syndicate of the University of Cambridge: Cambridge, UK, 2001.

16. IPCC (Intergovernmental Panel on Climate Change). Summary for Policymakers. In Climate Change 2007: The Physical Science Basis; Contribution of Working Group I to the Fourth Assessment Report of the Intergovernmental Panel on Climate Change; Solomon, S., Qin, M.M., Chen, M.M.Z., Averyt, K.B., Tignor, M., Miller, H.L., Eds.; Cambridge University Press: Cambridge, UK; New York, NY, USA, 2007; pp. 1-18.

17. Paeth, H.; Hall, N.M.; Gaertner, M.A.; Alonso, M.D.; Moumouni, S.; Polcher, J.; Ruti, P.M.; Fink, A.H.; Gosset, M.; Lebel, T.; et al. Progress in regional downscaling of West African precipitation Progress in regional downscaling of west African precipitation. Atmos. Sci. Lett. 2016, 12, 75-82. [CrossRef]

18. Louis, J.-F. A Parametric Model of Vertical Fluxes in the atmosphere. Bound. Layer Meteorol. 1979, 17, $187-202$. [CrossRef]

19. Dayan, U.; Nissen, K.; Ulbrich, U. Review Article: Atmospheric conditions inducing extreme precipitation over the eastern and western Mediterranean. Nat. Hazards Earth Syst. Sci. 2015, 15, 2525-2544. [CrossRef]

20. Katz, R.W.; Parlange, M.B.; Naveau, P. Statistics of extremes in hydrology. Adv. Water Ressour. 2002, 25, 1287-1304. [CrossRef]

21. Fowler, H.J.; Blenkinsop, S.; Tebaldi, C. Linking climate change modelling to impacts studies: Recent advances in downscaling techniques for hydrological. Int. J. Climatol. 2007, 27, 1547-1578. [CrossRef]

22. Lebel, T.; le Barbé, L.; Delclaux, F.; Polcher, J. From GCM scales to hydrological scales: Rainfall variability in West Africa. Stoch. Environ. Res. Risk Assess. 2000, 14, 275-295. [CrossRef]

23. Paeth, H.; Scholten, A.; Friederichs, P.; Hense, A. Uncertainties in climate change prediction: El Niño-Southern Oscillation and monsoons. Glob. Planet. Chang. 2008, 60, 265-288. [CrossRef]

24. Camberlin, P.; Fauchereau, N.; Gabriel, S. Empirical predictability study of October-December East African rainfall. Q. J. R. Meteorol. Soc. 2002, 128, 2239-2256.

25. Girmes, H.; Robin, P. Improving Seasonal Forecasting in the Low Latitudes. Mon. Weather Rev. 2006, 134, 1859-1879.

26. Paeth, H.; Diederich, M. Postprocessing of simulated precipitation for impact research in West Africa. Part II: A weather generator for daily data. Clim. Dyn. 2011, 36, 1337-1348. [CrossRef]

27. López-Moreno, J.I.; Beniston, M. Daily precipitation intensity projected for the 21st century: Seasonal changes over the Pyrenees. Theor. Appl. Climatol. 2009, 95, 375-384. [CrossRef]

28. Olume, V. Hydrological Processes in Regional Climate Model Simulations of the Central United States Flood of June-July 1993. J. Hydrometeorol. 2003, 4, 584-598. 
29. Fowler, H.J.; Ekström, M.; Kilsby, C.G.; Jones, P.D. New estimates of future changes in extreme rainfall across the UK using regional climate model integrations. 1. Assessment of control climate. J. Hydrol. 2005, 300, 212-233. [CrossRef]

30. Dee, D.P.; Uppala, S.M.; Simmons, A.J.; Berrisford, P.; Poli, P.; Kobayashi, S.; Andrae, U.; Balmaseda, M.A.; Balsamo, G.; Bauer, D.P.; et al. The ERA-Interim reanalysis: Configuration and performance of the data assimilation system. Q. J. R. Meteorol. Soc. 2011, 137, 553-597. [CrossRef]

31. Vose, R.S.; Schmoyer, R.L.; Steurer, P.M.; Peterson, T.C.; Heim, R.; Karl, T.R.; Eischeid, J.K. The Global Historical Climatology Network: Long-Term Monthly Temperature, Precipitation, Sea Level Pressure, and Station Pressure Data; Oak Ridge National Lab., TN (United States). Carbon Dioxide Information Analysis Center: Washington, DC, USA, 1992.

32. Pendergrass Angeline, The Climate Data Guide: GPCP (Monthly): Global Precipitation Climatology Project, National Center for Atmospheric Research Staff (Eds.), Last Modified 02 July 2016. 2016. Available online: https://climatedataguide.ucar.edu/climate-data/gpcp-monthly-global-precipitation-climatologyproject. (accessed on 2 January 2018).

33. New, M.; Lister, D.; Hulme, M.; Makin, I. A high-resolution data set of surface climate over global land areas. Clim. Res. 2002, 21, 1-25. [CrossRef]

34. Simmons, A.J.; Jones, P.D.; Bechtold, V.C.; Beljaars, A.C.M.; Ka, P.W. Comparison of trends and low-frequency variability in CRU, ERA-40, and NCEP//NCAR analyses of surface air temperature. J. Geophys. Res. 2004, 109, 1-18. [CrossRef]

35. Hewitt, C.D.; Griggs, D.J. Ensembles-based predictions of climate changes and their impacts. Eos 2004, 85, 566. [CrossRef]

36. Shahid, S. Trends in extreme rainfall events of Bangladesh. Theor. Appl. Climatol. 2011, 104, 489-499. [CrossRef]

37. Sciences, E.; Carolina, N.; Columbia, B.; Sciences, E.; Carolina, N. Avoiding Inhomogeneity in Percentile-Based Indices of Temperature Extremes. J. Clim. 2005, 18, 1641-1651.

38. Villarini, G.; Scoccimarro, E.; Gualdi, S. Projections of heavy rainfall over the central United States based on CMIP5 models. Atmos. Sci. Lett. 2013, 14, 200-205. [CrossRef]

39. Zolina, O.; Simmer, C.; Belyaev, K.; Kapala, A.; Gulev, S. Improving Estimates of Heavy and Extreme Precipitation Using Daily Records from European Rain Gauges. J. Hydrometeorol. 2009, 10, 701-716. [CrossRef]

40. Amoussou, E.; Camberlin, P.; Totin, V.S.H.; Pérard, J. Événements hydroclimatiques et risque d'inondation au sud-ouest du Bénin. In Proceedings of the 24ème colloque de l'Association Internationale de Climatologie, Rovereto, Italy, 6-10 September 2011; p. 2010.

41. Amoussou, E.; Tramblay, Y.; Totin, H.S.V.; Mahé, G. Dynamique et modélisation des crues dans le bassin du Mono à Nangbéto (Togo/Bénin). Hydrol. Sci. J. 2014, 59, 2060-2071. [CrossRef]

42. Fisher, R.A.; Tippett, L.H.C. Limiting forms of the frequency distribution in the largest particle size and smallest member of a sample. Proc. Camb. Phil. Soc. 1928, 24, 180-190. [CrossRef]

43. Nelder, J.A.; Mead, R. Nelder1965.pdf. Comput. J. 1965, 7, 308-313. [CrossRef]

44. Coles, S. An Introduction to Statistical Modeling of Extreme Values; Springer: London, UK, 2011; Volume 208.

45. Chu, P.S.; Zhao, X.; Ruan, Y.; Grubbs, M. Extreme rainfall events in the Hawaiian Islands. J. Appl. Meteorol. Climatol. 2009, 48, 502-516. [CrossRef]

46. Cunnane, C. Statistical Distributions for Flood Frequency Analysis; WMO Operational Hydrolofy report no. 33; the Secretariat of the Word Meteorological Organization: Geneva, Switzerland, 1989; pp. 581-582.

47. Jenkinson, A.F. The frequency distribution of the annual maximum (or minimum) values of meteorological elements. Q. J. R. Meteorol. Soc. 1955, 81, 158-171. [CrossRef]

48. El Adlouni, S.; Quarda, T.B.M.J. Comparaison des méthodes d'estimation des paramètres du modèle GEV non stationnaire. Rev. des Sci. l'Eau 2008, 21, 35-50. [CrossRef]

49. Ntajal, J.; Lamptey, B.L.; Mianikpo, J.; Kpotivi, W.K. R Ainfall T Rends and F Lood F Requency a Nalyses in the L Ower M Ono R Iver B Asin in T Ogo, W Est a Frica. Int. J. Adv. Res. 2016, 4, 1-11.

50. Davison, A. Bootstrap Methods and their Application, no. 1.; Cambridge University Press: Cambridge, UK, 1997.

51. Stedinger, J.R.; Vogel, R.M.; Foufoula-Georgiou, E. Frequency Anlysis of Extreme Events. In Handbook of Hydrology; Maidment, D.D.M.-H., Ed.; McGraw-Hill: New York, NY, USA, 1993; p. 68. 
52. Lamptey, B.L. Comparison of gridded multisatellite rainfall estimates with gridded gauge rainfall over West Africa. J. Appl. Meteorol. Climatol. 2008, 47, 185-205. [CrossRef]

53. Gbobaniyi, E.; Sarr, A.; Sylla, M.B.; Diallo, I.; Lennard, C.; Dosio, A.; Dhiédiou, A.; Kamga, A.; Klutse, N.A.; Hewitson, B.; et al. Climatology, annual cycle and interannual variability of precipitation and temperature in CORDEX simulations over West Africa. Int. J. Climatol. 2014, 34, 2241-2257. [CrossRef]

54. Diallo, I.; Sylla, M.B.; Giorgi, F.; Gaye, A.T.; Camara, M. Multimodel GCM-RCM ensemble-based projections of temperature and precipitation over West Africa for the Early 21st Century. Int. J. Geophys. 2012, 2012. [CrossRef]

55. Riede, J.O.; Posada, R.; Fink, A.H.; Kaspar, F. What's on the 5th IPCC Report for West Africa? In Adaptation to Climate Change and Variability in Rural West Africa; Springer: Cham, Switzerland, 2016; pp. 7-23.

56. Ruti, P.M.; Williams, J.E.; Hourdin, F.; Guichard, F.; Boone, A.; Van Velthoven, P.; Favot, F.; Musat, I.; Rummukainen, M.; Domínguez, M.; et al. The West African climate system: A review of the AMMA model inter-comparison initiatives. Atmos. Sci. Lett. 2011, 12, 116-122. [CrossRef]

57. Lafore, J.P.; Flamant, C.; Giraud, V.; Guichard, F.; Knippertz, P.; Mahfouf, J.F.; Mascart, P.; Williams, E.R. Introduction to the AMMA Special Issue on 'Advances in understanding atmospheric processes over West Africa through the AMMA field campaign'. Q. J. R. Meteorol. Soc. 2010, 136, 2-7. [CrossRef]

58. Angelina, A.; Djibo, A.G.; Seidou, O.; Sanda, I.S.; Sittichok, K. Modifications du régime d'écoulement du fleuve Niger à Koulikoro sous changement climatique. Hydrol. Sci. J. 2015, 60, 1709-1723. [CrossRef]

59. Sylla, M.B.; Nikiema, P.M.; Gibba, P.; Kebe, I.; Klutse, N.A.B. Climate Change over West Africa: Recent Trends and Future Projections. In Adaptation to Climate Change and Variability in Rural West Africa; Yaro, J.A., Hesselberg, J., Eds.; Springer International Publishing: Berlin, Germany, 2016; pp. 1-244.

60. Mahe, G. Mémoire Habilitation à Diriger des Recherches Variabilité pluie-débit en Afrique de l'Ouest et Centrale au 20ème siècle: Changements Hydro-Climatiques, Occupation du sol et Modélisation Hydrologique Université des Sciences et Techniques Gil Mahé. HDR Dissertation, Université des Sciences et Techniques Montpellier, Montpellier, France, 2015.

61. Yabi, I.; Afouda, F. Extreme rainfall years in Benin (West Africa). Quat. Int. 2012, 262, 39-43. [CrossRef]

62. Kasei, R.; Diekkrüger, B.; Leemhuis, C. Drought frequency in the Volta basin of West Africa. Sustain. Sci. 2010, 5, 89-97. [CrossRef]

63. Hourdin, F.; Musat, I.; Guichard, F.S.; Ruti, P.M.; Favot, F.; Filiberti, M.A.; Pham, M.; Grandpeix, J.Y.; Polcher, J.; Marquet, P.; et al. Amma-Model intercomparison project. Bull. Am. Meteorol. Soc. 2010, 91, 95-104. [CrossRef]

64. Tossou, E.M.; Ndiaye, M.L.; Traore, V.B.; Sambou, H.; Kelome, N.C.; SY, B.A.; Diaw, A.T. Characterisation and Analysis of Rainfall Variability in the Mono-Couffo River Watershed Complex, Benin (West Africa). Resour. Environ. 2017, 7, 13-29.

65. Fowler, H.J.; Wilby, R.L. Detecting changes in seasonal precipitation extremes using regional climate model projections: Implications for managing fluvial flood risk. Water Resour. Res. 2010, 46, 1-17. [CrossRef]

66. Frei, C.; Scho, R.; Fukutome, S.; Vidale, P.L. Future change of precipitation extremes in Europe: Intercomparison of scenarios from regional climate models. J. Geophys. Res. 2006, 111. [CrossRef]

67. Beniston, M.; Stephenson, D.B.; Christensen, O.B.; Ferro, C.A.; Frei, C.; Goyette, S.; Halsnaes, K.; Holt, T.; Jylhä, K.; Koffi, B.; et al. Future extreme events in European climate: An exploration of regional climate model projections. Clim. Chang. 2007, 81, 71-95. [CrossRef]

68. Burn, D.H. The use of resampling for estimating confidence intervals for single site and pooled frequency analysis/Utilisation d' un rééchantillonnage pour l' estimation des intervalles de confiance lors d' analyses fréquentielles mono et multi-site intervals f. Hydrol. Sci. Sci. Hydrol. 2003, 48, 25-38. [CrossRef]

69. Caya, D.; Laprise, R. A semi-implicit semi-Lagrangian regional climate model: The Canadian RCM. Mon. Weather Rev. 1999, 127, 341-362. [CrossRef]

70. Hall, M.J.; Van den Boogaard, H.F.; Fernando, R.C.; Mynett, A.E. The construction of confidence intervals for frequency analysis using resampling techniques to cite this version: HAL Id: Hal-00304907 The construction of confidence intervals for frequency analysis using resampling techniques. Hydrol. Earth Syst. Sci. 2004, 8, 235-246. [CrossRef]

71. Sylla, M.B.; Gaye, A.T.; Jenkins, G.S. On the fine-scale topography regulating changes in atmospheric hydrological cycle and extreme rainfall over West Africa in a regional limate model projections. Int. J. Geophys. 2012. [CrossRef] 
72. Ekström, M.; Fowler, H.J.; Kilsby, C.G.; Jones, P.D. New estimates of future changes in extreme rainfall across the UK using regional climate model integrations. 2. Future estimates and use in impact studies. J. Hydrol. 2005, 300, 234-251. [CrossRef]

73. Emori, S.; Hasegawa, A.; Suzuki, T.; Dairaku, K. Validation, parameterization dependence, and future projection of daily precipitation simulated with a high-resolution atmospheric GCM. Geophys. Res. Lett. 2005, 32, 1-4. [CrossRef]

74. Kodja, D.J. Indicateurs des Évènements Hydroclimatiques Extrêmes dans le Bassin Versant de l'Ouémé à l'exutoire de Bonou en Afrique de l'Ouest. Ph.D. Dissertation, Université of Montpellier, Montpellier, France, 2018.

75. Embrechts, P.; Klüppelberg, C.; Mikosch, T.; Emberchts, P.; Klüppelberg, C.; Mikosch, T. Modelling Extremal Events. In Statistical Methods for Extremal Events; Springer: Berlin/Heidelberg, Germany; NewYork, NY, USA; London, UK; Paris, France; Tokyo, Janpan; Hong Kong, China; Barcelona, Spain; Budapest, Hungary, 1997; pp. 283-370.

76. Zwiers, F.W.; Kharin, V.V. Changes in the Extremes of the Climate Simulated by CCC GCM2 under $\mathrm{CO}_{2}$ Doubling. J. Clim. 1998, 2, 2200-2222. [CrossRef]

77. Amoussou, E.; Camberlin, P.; Mahe, G. Impact de la variabilité climatique et du barrage Nangbéto sur 1' hydrologie du système Mono-Couffo (Afrique de l' Ouest). Hydrol. Sci. J. 2012, 57, 805-817.

78. Kendall, M.; Stuart, A. Analysis Multivariate; Griffin, C., Ed.; Charles Griffim \& Company Ltd.: London, UK, 1975.

(C) 2020 by the authors. Licensee MDPI, Basel, Switzerland. This article is an open access article distributed under the terms and conditions of the Creative Commons Attribution (CC BY) license (http://creativecommons.org/licenses/by/4.0/). 